\title{
Periodical Public Opinion Survey on Nuclear Energy (Inhabitants Living in the Tokyo Metropolitan Area)
}

\author{
Yoshihiko SHINODA ${ }^{1,2,3, *}$, Shouji TSUCHIDA ${ }^{4}$ and Hiroshi KIMURA ${ }^{5}$ \\ ${ }^{1}$ Wakasa Wan Energy Research Center, 64-52-1 Nagatani, Tsuruga-shi, Fukui 914-0192, Japan \\ ${ }_{2}^{2}$ Nuclear Power and Energy Safety Engineering, University of Fukui, 3-9-1 Bunkyo, Fukui-shi, Fukui 910-8507, Japan \\ ${ }^{3}$ Japan Atomic Energy Agency, Tsuruga Head Office, 65-20 Kizaki, Tsuruga-shi, Fukui 914-8585, Japan \\ ${ }^{4}$ Graduate School and Faculty of Safety Science, Kansai University, 7-1 Hakubai-cho Takatsuki-shi, Osaka 569-1098, Japan \\ ${ }^{5}$ Public Outreach, NPO, 1-1-11 Nedsu, Bunkyou-ku, Tokyo 113-0031, Japan
}

\begin{abstract}
Fukushima Daiichi Nuclear Power Plant Accident (Fukushima Accident) has brought about a great change in many people's perceptions about nuclear power plant safety. When discussing future energy options for Japan, it is important to have a full grasp of the attitude of a large number of people towards nuclear energy. The Atomic Energy Society of Japan has conducted annual questionnaire survey of 500 adults who live within 30 kilometers of Tokyo Station. The aim of this survey is to assess trends in public attitude towards nuclear energy. The authors that designed the questionnaire entries of this survey have been managing questionnaire data as members of the Data Management Working Group under the Social and Environmental Division of the Atomic Energy Society of Japan. We confirmed the change in public attitude towards nuclear energy through this periodical survey after the Fukushima Accident. In particular, public concerns about the use of nuclear energy increased after the Fukushima Accident, and many people have raised doubts over the use of nuclear energy in the future.
\end{abstract}

KEYWORDS: nuclear energy, survey of public opinion, trends in public attitude, Fukushima Daiichi Nuclear Power Plant Accident

\section{Introduction}

An awareness survey called the "Survey on Energy and Nuclear Power" (hereinafter referred to as the "Survey") was conducted each year between 2007 and 2012 to examine and analyze trends in the public's attitudes to energy and nuclear power ${ }^{1,2)}$. The survey was conducted by a special committee (Atomic Energy Society of Japan) that examined the "Development and expansion of a database on mass media reports and public opinion about nuclear power" up until 2011 and has been led by another special committee (Atomic Energy Society of Japan) that has conducted an "Awareness survey and analysis of citizens and professionals" since 2012.

In March 2011, the Great East Japan Earthquake occurred, followed by the accident at the

* Corresponding author, E-mail: shinoda.yoshihiko@plum.plala.or.jp

DOI : 10.15669/fukushimainsights. Vol.4.255

(C) 2021 Atomic Energy Society of Japan. All rights reserved.

Originally published in Transactions of the Atomic Energy Society of Japan (ISSN 1347-2879), Vol. 13, No. 3, p.94-112

(2014) in Japanese. (Japanese version accepted: April 30, 2014) 
Fukushima Daiichi Nuclear Power Plants (hereinafter referred to as the "Fukushima Accident"). The Fukushima Accident caused extensive damage and was thought to have significantly changed people's attitudes to nuclear power, which created the need to continuously explore how nuclear power should be used in the future. Knowing that attitudes and awareness changed before, during and after the accident is useful for discussion within society to explore how nuclear power should be used in the future. It is desirable that a study that seeks to understand these changes in public awareness is based on information obtained by conducting consistent surveys, in line with the method commonly employed in social surveys, over a period of several years both before after the Fukushima Accident.

Regular awareness surveys on whether nuclear power should be used have been performed by various organizations, including the Cabinet Office ${ }^{3)}$, Japan Productivity Center for Socio-Economic Development ${ }^{4)}$ (its name was changed to the Japan Productivity Center in 2009), the Research Council for Energy and Information Technology ${ }^{5)}$ (dissolved in October 2011), the Institute of Applied Energy 6), Institute of Nuclear Safety System Incorporat$\mathrm{ed}^{7}$, and the Japan Atomic Energy Relations Organization ${ }^{8}$. Among the studies that analyzed and discussed changes in attitudes and awareness most probably caused by the impact of the Fukushima Accident are Kitada's ${ }^{9)}$, from the Institute of Nuclear Safety System Incorporated, and Yokote's ${ }^{10)}$, from Japan Atomic Energy Relations Organization. Their findings are based on the results of surveys conducted around the time of the Fukushima Accident.

Kitada discusses the impact of the Fukushima Accident based on the results of fourteen surveys conducted between 1993 and December 2011. She conducted two surveys after the accident targeting residents in areas where the Kansai Electric Power Company (KEPCO) supplies electricity and evaluated the changes in attitudes four and seven months after the accident.

Yokote reported changes in awareness and attitudes based on the results of six nationwide surveys conducted between January 2007 and November 2012. After the accident, surveys were conducted twice, once in November 2011 and again in November 2012. In these surveys, there was no question that directly asked whether nuclear power should continue to be used. Instead, the question was directed at ascertaining if the respondents thought that nuclear energy was necessary and whether they were for or against the use of nuclear power. No survey was published after the accident by the Cabinet Office, the Japan Productivity Center for Socio-Economic Development, the Research Council for Energy and Information Technology, or the Institute of Applied Energy.

However, due to the increased public interest in the trends and status of the national energy policy after the Fukushima Accident, surveys are being actively conducted, mainly by the media. For example, the NHK Broadcasting Culture Research Institute performed telephone surveys in June 2011, October 2011, and March 2012, referred to as the Awareness Survey on Nuclear and Energy ${ }^{11}$, and published the results after the Fukushima Accident. However, since there is no information about public attitudes and awareness before the accident, this limits the extent to which the impact of the accident can be discussed.

In this study, all surveys use the same sampling method and respondents use the same selection method with the focus on understanding changes in attitudes and awareness over time. Five surveys were performed between May 2007 and January 2011 (before the accident) and two surveys were performed after the accident, in January 2012 and January 2013. They were conducted on a regular basis, at almost equal intervals. The surveys include questions that directly ask whether respondents think nuclear power should continue to be used as well as questions designed to ascertain the respondents' attitudes and awareness regarding nuclear power. The responses will be useful in a structural analysis of respondents' attitudes, to identify whether they are for or against the use of nuclear power. From these perspectives, the results of the 
survey and analysis will be useful and very distinctive basic information.

These surveys facilitate discussions on the trends and status of public opinion about longterm nuclear use over a period of several years around the time of the accident. It is one of the few studies that attempts to delve into the respondents' subconscious mind based on a diverse range of questions. The study aims to examine factors that have an impact on the development of a social consensus on nuclear power use from a macro viewpoint by analyzing changes in awareness and attitudes in society, over time, based on the surveys.

\section{Survey Results}

\section{Survey Overview}

The survey participants were selected from the general public, were aged 20 years or older, and lived within a 30-kilometer radius of Tokyo Station. Quota sampling was used in line with the demographic composition of the survey audience and 500 sample results were acquired using the leaving method. The area covered 23 Wards from Tokyo to Tachikawa City, Yokohama City in Kanagawa Prefecture, Saitama City in Saitama Prefecture, and Narashino City in Chiba Prefecture. This is one of the patterns that defines the Tokyo area as a large metropolitan conurbation. In this study, the survey area is referred to as the "Tokyo metropolitan area within a 30-kilometer radius". The survey has been conducted every year and the overview, including the survey periods, is provided in Table 1.

The impact of The Fukushima Accident can be evaluated and analyzed based on the survey results. Moreover, following the sixth survey conducted in January 2013, about two years after the Fukushima Accident, we can obtain information on how public awareness and attitudes have evolved since any initial changes immediately following the accident. Furthermore, in July 2007, between the first survey in May 2007 and second survey in December 2008, the Niigata Chuetsu-oki Earthquake occurred, and we can compare the impact of this earthquake with that of the Fukushima Accident.

The survey conducted as part of this study included questions used in all the other six surveys (hereinafter referred to as repeated questions) and additional or revised questions (hereinafter referred to as topic questions). Some questions do not appear in all the surveys and the form questions take is not necessarily identical; for example, the question sequence of repeated questions may change due to the relation to topic questions. Taking this into account, the study discusses the results of the repeated questions and elucidates the impact of the Fukushima Accident and changes in public attitudes and awareness changes over time of those living within a 30-kilometer radius in the Tokyo metropolitan area.

Table 1 Survey overview of the residents living in the Tokyo metropolitan area

\begin{tabular}{cccc}
\hline \# of times & Survey period & \#of samples & Methods \\
\hline First & May 2007 & 500 & Leaving \\
\hline Second & Niigata Chuetsu-oki Earthquake (July 2007) & Leaving \\
\hline Third & December 2008 & 500 & Leaving \\
\hline Fourth & January 2010 & 500 & Leaving \\
\hline & January 2011 & 500 & Leaving \\
\hline Fifth & Great East Japan Earthquake and the Fukushima Accident & Larch 2011) & \\
\hline Sixth & January 2012 & 500 & 500 \\
\hline
\end{tabular}




\section{Overview and Results of Repeated Questions}

\section{(1) Questions on interest in, promotion, usefulness, and safety of nuclear power}

The common questions in this survey consisted of four items; "level of interest", "need to promote nuclear power", "usefulness/necessity", and "safety/anxiety". They are hereinafter referred to as interest, promotion, usefulness, and safety. Appendix A shows some of the actual questions excerpted from the survey forms. In the question form, we tried to minimize distortion caused by one-sided questions; for example, by using a neutral question text, "Are you interested in nuclear power or not?" we tried to ascertain if the respondent had any interest or not. Then, we provided multiple choice options "(A) I am interested”, "(B) I am somewhat interested”, “(C) Neither”, “(D) I am not particularly interested” and "(E) I am not interested”.

All the questions have five response options provided in the order from positive to negative, including a neutral response.

The letters (A) through (E), prefixed with the answer options, have been added in this study report only to distinguish them and do not appear on the actual survey forms. Tables 2 through 5 show changes over time in the survey results for the four question items. In some questions, the total percentage of the five answer results does not total $100 \%$, due to some invalid answers and rounding errors.

The answer options for these questions are based on an ordinal scale, not on an interval scale, in a strict sense. Or, even if they are on an interval scale, the intervals (difference) between options are not perfectly even. They are bipolar (ensuring the symmetry of response options) 5-point scale options with the neutral response "Neither" as option (C). In this survey, we analyzed the scores assigned to the 5 options, from -2 to 2 , at one-point intervals. In this case, in order to evaluate and analyze the responses as numerical information, a negative score represents a positive direction, a positive score represents a negative direction, and 0 was considered neutral (mid-point). This approach to scoring is referred to as the semantic differential (SD) method and is often used in psychology experiments; accordingly, it can be regarded as a reasonable method in this context also.

Table 2 Responses to the question on respondent's level of interest in nuclear power

\begin{tabular}{|c|c|c|c|c|c|c|}
\hline \multirow{2}{*}{$\begin{array}{l}\text { Level of interest } \\
\text { Options and response rate }\end{array}$} & \multicolumn{4}{|c|}{ Before the Fukushima Accident } & \multicolumn{2}{|c|}{ After the Accident } \\
\hline & First & Second & Third & Fourth & Fifth & Sixth \\
\hline (A) I am interested & $12.6 \%$ & $11.4 \%$ & $10.4 \%$ & $10.4 \%$ & $29.2 \%$ & $27.8 \%$ \\
\hline (B) I am somewhat interested & $29.8 \%$ & $26.4 \%$ & $28.2 \%$ & $27.6 \%$ & $35.4 \%$ & $44.2 \%$ \\
\hline (C) Neither & $35.0 \%$ & $34.4 \%$ & $30.8 \%$ & $29.6 \%$ & $25.8 \%$ & $21.0 \%$ \\
\hline (D) I am not particularly interested & $16.4 \%$ & $20.2 \%$ & $21.2 \%$ & $23.0 \%$ & $7.6 \%$ & $6.2 \%$ \\
\hline (E) I am not interested & $6.0 \%$ & $7.4 \%$ & $9.4 \%$ & $9.4 \%$ & $1.8 \%$ & $0.6 \%$ \\
\hline Invalid answers & $0.2 \%$ & $0.2 \%$ & - & - & $0.2 \%$ & $0.2 \%$ \\
\hline
\end{tabular}

Table 3 Responses to the question regarding the need to promote the use of nuclear power

\begin{tabular}{|c|c|c|c|c|c|c|}
\hline Need to promote nuclear power & \multicolumn{4}{|c|}{ Before the Fukushima Accident } & \multicolumn{2}{|c|}{ After the Accident } \\
\hline Options and Response rate & First & Second & Third & Fourth & Fifth & Sixth \\
\hline (A) Should use & $14.4 \%$ & $13.2 \%$ & $11.2 \%$ & $14.2 \%$ & $5.8 \%$ & $5.6 \%$ \\
\hline (B) May consider using & $28.8 \%$ & $28.6 \%$ & $28.6 \%$ & $29.6 \%$ & $14.8 \%$ & $17.6 \%$ \\
\hline (C) Neither & $39.8 \%$ & $42.0 \%$ & $43.0 \%$ & $42.4 \%$ & $30.4 \%$ & $26.6 \%$ \\
\hline (D) May consider stop using & $13.2 \%$ & $12.6 \%$ & $12.2 \%$ & $11.2 \%$ & $27.0 \%$ & $31.2 \%$ \\
\hline (E) Should stop using & $3.8 \%$ & $3.6 \%$ & $5.0 \%$ & $2.6 \%$ & $21.8 \%$ & $19.0 \%$ \\
\hline Invalid answers & - & - & - & - & $0.2 \%$ & - \\
\hline
\end{tabular}


Table 4 Responses to the question regarding the usefulness/necessity of nuclear power

\begin{tabular}{|c|c|c|c|c|c|c|}
\hline Usefulness/Necessity & \multicolumn{4}{|c|}{ Before the Fukushima Accident } & \multicolumn{2}{|c|}{ After the Accident } \\
\hline Options and Response rate & First & Second & Third & Fourth & Fifth & Sixth \\
\hline (A) I think it is useful & $21.8 \%$ & $17.0 \%$ & $17.2 \%$ & $21.2 \%$ & $11.2 \%$ & $11.2 \%$ \\
\hline (B) I think it is somewhat useful & $37.2 \%$ & $38.4 \%$ & $37.0 \%$ & $40.6 \%$ & $29.6 \%$ & $30.4 \%$ \\
\hline (C) Neither & $34.2 \%$ & $37.8 \%$ & $37.2 \%$ & $32.8 \%$ & $34.8 \%$ & $32.8 \%$ \\
\hline (D) I think it is somewhat unnecessary. & $5.6 \%$ & $4.8 \%$ & $5.6 \%$ & $4.4 \%$ & $13.2 \%$ & $14.2 \%$ \\
\hline (E) I think it is unnecessary & $1.2 \%$ & $2.0 \%$ & $3.0 \%$ & $1.0 \%$ & $11.0 \%$ & $11.4 \%$ \\
\hline Invalid answers & - & - & - & - & $0.2 \%$ & - \\
\hline
\end{tabular}

Table 5 Responses to the question regarding safety/anxiety about nuclear power

\begin{tabular}{|c|c|c|c|c|c|c|}
\hline Safety/anxiety & \multicolumn{4}{|c|}{ Before the Fukushima Accident } & \multicolumn{2}{|c|}{ After the Accident } \\
\hline Options and Response rate & First & Second & Third & Fourth & Fifth & Sixth \\
\hline (A) I feel it is safe & $3.4 \%$ & $2.6 \%$ & $0.8 \%$ & $1.6 \%$ & $0.6 \%$ & $0.4 \%$ \\
\hline (B) I feel it is somewhat safe & $8.6 \%$ & $14.2 \%$ & $14.2 \%$ & $17.0 \%$ & $4.6 \%$ & $5.6 \%$ \\
\hline (C) Neither & $35.0 \%$ & $33.8 \%$ & $34.8 \%$ & $31.6 \%$ & $24.0 \%$ & $20.2 \%$ \\
\hline (D) I feel somewhat anxious & $37.4 \%$ & $36.2 \%$ & $39.0 \%$ & $39.0 \%$ & $35.4 \%$ & $40.0 \%$ \\
\hline (E) I feel anxious & $15.4 \%$ & $13.2 \%$ & $11.2 \%$ & $10.8 \%$ & $35.4 \%$ & $33.8 \%$ \\
\hline Invalid answers & $0.2 \%$ & - & - & - & - & - \\
\hline
\end{tabular}

(2) Questions to ascertain the respondents' level of agreement with statements on the use of nuclear power

Next, in this survey, we provided general statements on the use of nuclear power as answers to questions designed to ascertain the respondents' levels of agreement or disagreement. Some of the actual questions are listed in the Appendix B. In these questions, we provided six answer options to show their level of agreement given in the order from agreement to disagreement and another option to show their lack of opinion/neutrality regarding the statement in question: "I don't know". In the surveys, these questions immediately follow the questions on the respondents' interest in and perception of the safety of nuclear power mentioned in the previous section II-2-(1).

In this study, we discuss the questions based on the responses that "I have confidence in the security consciousness and efforts of those who are engaged in the generation of nuclear power" (hereinafter referred to as "trust"), and "It is dangerous to have nuclear power plants in a country like Japan, which experiences frequent earthquakes" (hereinafter referred to as "risk of earthquake"). It is often reported ${ }^{12)}$ that the sense of trust has a strong direct or indirect impact on attitudes about nuclear power. The above-stated four questions do not include the perspective of trust in nuclear power. Therefore, through the questions on trust in those who are engaged in nuclear power, an attempt was made to evaluate the impact of public trust in nuclear power. Here, we regard public trust in those who are engaged in ensuring the safety (so-called "risk manager") of nuclear power as representing confidence in nuclear power. Moreover, this study focuses on discussing the impact of the Fukushima Accident. We consider that direct questions about the risk of earthquakes are important, and therefore, intend to discuss them in this paper.

Figure 1 shows the changes over time in the response rates for "trust" and "risk of earthquake". In the graph, the answer options (A), (B), (C), (D), (E) and (F) correspond to "I agree", "I somewhat agree", "Neither", "I somewhat agree", "I disagree", and "I don't know", respectively.

The lines that connect each symbol indicating time of measurement $(\boldsymbol{\bullet}, \square$, $\diamond$, etc.) distinguish between respective options. 


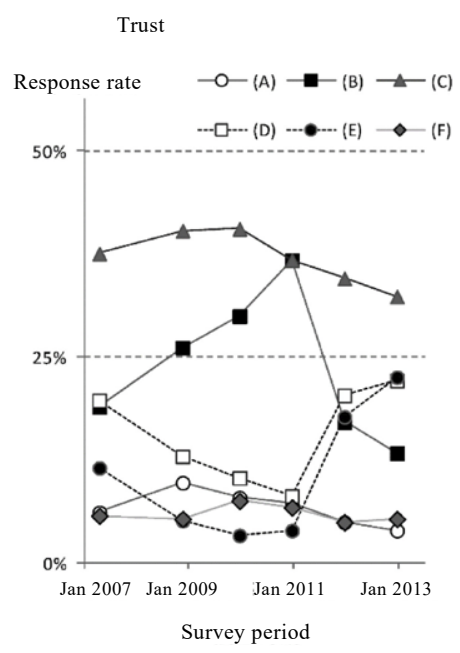

(1) Trust

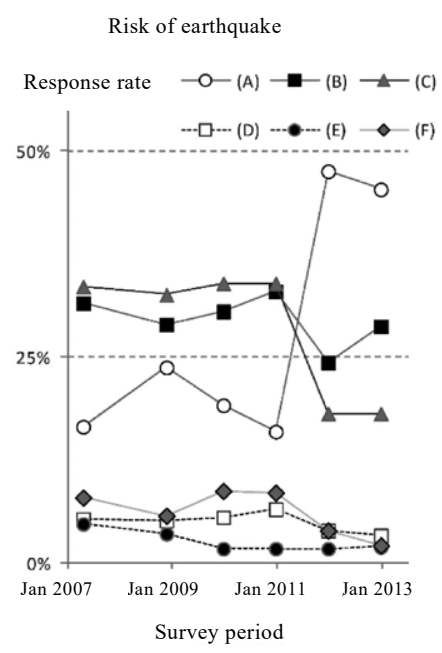

(2) Risk of earthquake

Figure 1 Examples of changes over time in the level of agreement on the use of nuclear power

(3) Questions on matters that respondents are interested in and/or are concerned about in everyday life

Examples of the questions that ask about respondents' interests and concerns about matters in society are provided in Appendix C. These questions included answer options such as Imported food, Sickness, Nuclear power, Nuclear-related accidents, Natural disasters, and Traffic accidents and the respondents had to choose all options that were applicable to them, with no restriction on the number of options they could select. Note that some of the answer options were changed in the course of the study and all surveys did not include exactly the same questions.

However, there is no change in the major topics of the questions, and we handle matters that have not changed as continuously evaluable questions. Figure 2 shows the changes over time in the responses to questions on interest in and concerns about Imported food, Sickness, Nuclear power, and Nuclear-related accidents as representative and characteristic matters of evaluable questions. These questions are provided at the beginning of all the surveys.

\section{Analysis and Evaluation of Survey Results}

\section{Analysis and Evaluation of Repeated Questions}

(1) Analysis and evaluation of awareness and attitudes in relation to interest in, promotion, usefulness, and safety of nuclear power

(a) Analysis and evaluation of survey results

a) Analysis and evaluation of changes in responses

Table 6 shows statistically tested results of changes in the responses between the surveys shown in Tables 2 to 5 . In Table $6,++(--)$ represents the increase (decrease) in the response rate, with $99 \%$ confidence, and $+(-)$ represents the increase (decrease) in response rate, with $95 \%$ confidence.

Each question item showed significant changes around the time of the Fukushima Accident. 


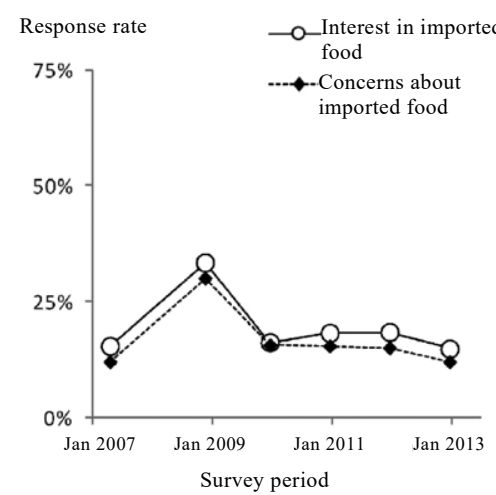

(1) Interest in/Concerns about imported food

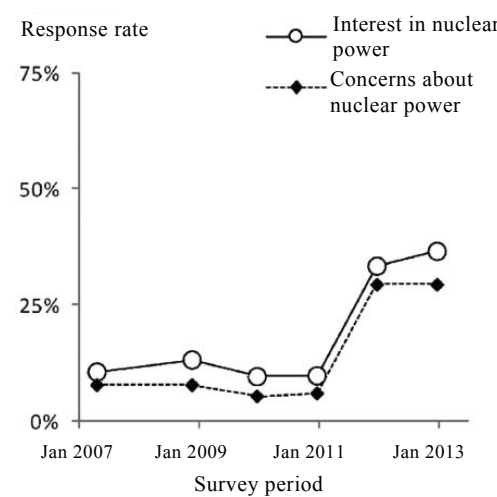

(3) Interest in/Concerns about nuclear power

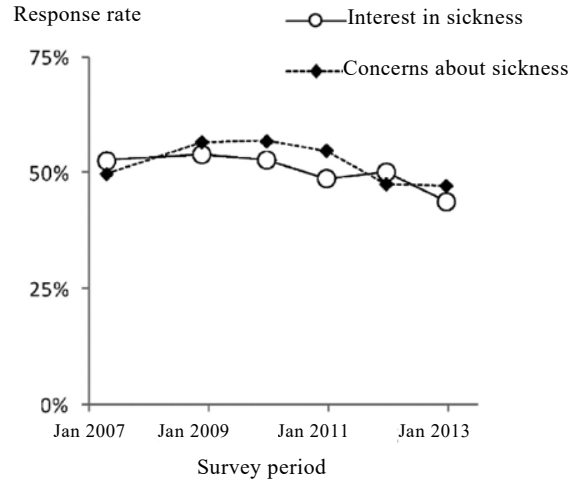

(2) Interest in/Concerns about sickness

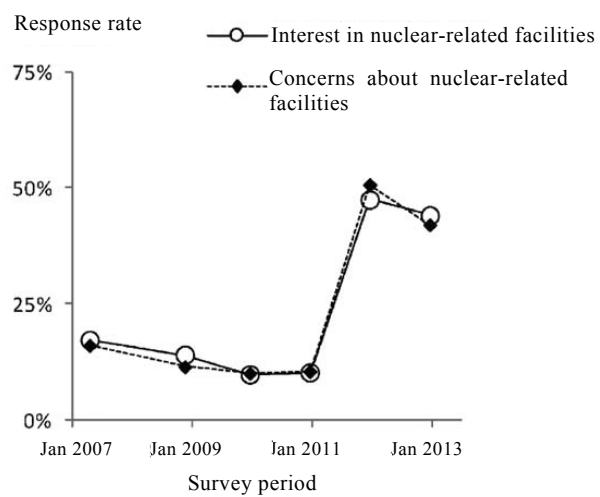

(4) Interests in/Concerns about nuclear-related facilities

Figure 2 Changes over time in response rates on matters that respondents have interest in and concerns about in everyday life

Table 6 Changes in response rates

\begin{tabular}{|c|c|c|c|c|c|c|c|c|c|c|c|}
\hline \multicolumn{6}{|c|}{ (1) Level of interest } & \multicolumn{6}{|c|}{ (2) Need to promote nuclear power } \\
\hline $\begin{array}{l}\text { Test of } \\
\text { significant } \\
\text { differences in } \\
\text { response rate } \\
\text { changes }\end{array}$ & $\begin{array}{c}\text { First } \\
\downarrow \\
\text { Second }\end{array}$ & $\begin{array}{c}\text { Second } \\
\downarrow \\
\text { Third }\end{array}$ & $\begin{array}{c}\text { Third } \\
\downarrow \\
\text { Fourth }\end{array}$ & $\begin{array}{c}\text { Fourth } \\
\downarrow \text { Accident } \\
\text { Fifth }\end{array}$ & $\begin{array}{c}\text { Fifth } \\
\quad \downarrow \\
\text { Sixth }\end{array}$ & $\begin{array}{c}\text { Test of } \\
\text { significant } \\
\text { differences in } \\
\text { response rate } \\
\text { changes }\end{array}$ & $\begin{array}{c}\text { First } \\
\downarrow \\
\text { Second }\end{array}$ & $\begin{array}{c}\text { Second } \\
\downarrow \\
\text { Third }\end{array}$ & $\begin{array}{c}\text { Third } \\
\downarrow \\
\text { Fourth }\end{array}$ & $\begin{array}{c}\text { Fourth } \\
\downarrow \text { Accident } \\
\text { Fifth }\end{array}$ & $\begin{array}{c}\text { Fifth } \\
\quad \downarrow \\
\text { Sixth }\end{array}$ \\
\hline (A) & & & & ++ & & (A) & & & & -- & \\
\hline (B) & & & & ++ & ++ & (B) & & & & -- & \\
\hline (C) & & & & & & (C) & & & & -- & \\
\hline (D) & & & & -- & & (D) & & & & ++ & \\
\hline (E) & & & & -- & & (E) & & & - & ++ & \\
\hline \multicolumn{6}{|c|}{ (3) Usefulness/necessity } & \multicolumn{6}{|c|}{ (4) Safety/anxiety } \\
\hline $\begin{array}{c}\text { Test of } \\
\text { significant } \\
\text { differences in } \\
\text { response rate } \\
\text { changes }\end{array}$ & $\begin{array}{c}\text { First } \\
\downarrow \\
\text { Second }\end{array}$ & $\begin{array}{c}\text { Second } \\
\downarrow \\
\text { Third }\end{array}$ & $\begin{array}{c}\text { Third } \\
\downarrow \\
\text { Fourth }\end{array}$ & $\begin{array}{c}\text { Fourth } \\
\downarrow \text { Accident } \\
\text { Fifth }\end{array}$ & $\begin{array}{c}\text { Fifth } \\
\quad \downarrow \\
\text { Sixth }\end{array}$ & $\begin{array}{c}\text { Test of } \\
\text { significant } \\
\text { differences in } \\
\text { response rate } \\
\text { changes }\end{array}$ & $\begin{array}{c}\text { First } \\
\downarrow \\
\text { Second }\end{array}$ & $\begin{array}{c}\text { Second } \\
\downarrow \\
\text { Third }\end{array}$ & $\begin{array}{c}\text { Third } \\
\downarrow \\
\text { Fourth }\end{array}$ & $\begin{array}{c}\text { Fourth } \\
\downarrow \text { Accident } \\
\text { Fifth }\end{array}$ & $\begin{array}{c}\text { Fifth } \\
\downarrow \\
\text { Sixth }\end{array}$ \\
\hline (A) & & & & -- & & (A) & & - & & & \\
\hline (B) & & & & -- & & (B) & ++ & & & -- & \\
\hline (C) & & & & & & (C) & & & & -- & \\
\hline (D) & & & & ++ & & (D) & & & & & \\
\hline (E) & & & - & ++ & & (E) & & & & ++ & \\
\hline
\end{tabular}

$++(--)$ : Increase (decrease) with $99 \%$ confidence, $+(-)$ : Increase (decrease) with $95 \%$ confidence 
Such changes are probabilistically unlikely to be a coincidence. However, there were only a few significant changes before the accident. Before the Fukushima Accident, option (E) decreased between the third and fourth surveys for both Promotion and Usefulness, option (B) significantly increased in the first and second surveys for Safety, and option (A) decreased between the second and third surveys.

As unique features for changes around the time of the Fukushima Accident, option (C) showed no changes for Interest and Usefulness but there were changes (decreased) for Promotion and Safety, and option (D) (weak negative answer = "I am somewhat concerned") showed no changes for Safety. If we assume that the pattern of changes for option (C) was caused by hesitation, we can say that people no longer hesitated when deciding how to respond to questions regarding Promotion and Safety.

b) Analysis and evaluation by assigning scores to options

Scores were assigned to options, the total scores of each respondents' answers were calculated and the (arithmetic) means and unbiased variances are listed in Table 7. The means represent the positive/negative trends of all respondents; the values and positive/negative directions made the trends in attitudes/awareness easy to understand. Unbiased variances were the measure of degree of dispersion among responses.

For example, although Promotion was assigned negative values up until the fourth survey before the Fukushima Accident, values turned positive in the fifth and sixth surveys. This shows that many people were positive about promoting nuclear power before the Fukushima Accident, but overall attitudes about the promotion of nuclear power shifted in a negative direction

Table 7 Overall survey trends based on scores assigned to answer options (Means and unbiased variances)

(1) Level of interest

\begin{tabular}{|c|c|c|c|c|c|}
\hline & \multicolumn{4}{|c|}{ Before the Fukushima Accident } & \multirow{2}{*}{$\begin{array}{c}\text { After the Accident } \\
\text { Fifth Sixth }\end{array}$} \\
\hline & First & Second & Third & Fourth & \\
\hline Mean & -0.27 & -0.14 & -0.09 & -0.07 & $-0.83-0.92$ \\
\hline $\begin{array}{l}\text { Unbiased } \\
\text { variance }\end{array}$ & 1.14 & 1.20 & 1.28 & 1.30 & $0.99 \quad 0.79$ \\
\hline
\end{tabular}

(2) Need to promote nuclear power

\begin{tabular}{|c|c|c|c|c|c|c|}
\hline & \multicolumn{4}{|c|}{ Before the Fukushima Accident } & \multicolumn{2}{|c|}{ After the Accident } \\
\hline & First & Second & Third & Fourth & Fifth & Sixth \\
\hline Mean & -0.37 & -0.35 & -0.29 & -0.42 & 0.44 & 0.40 \\
\hline $\begin{array}{l}\text { Unbiased } \\
\text { variance }\end{array}$ & 1.01 & 0.96 & 0.98 & 0.91 & 1.33 & 1.31 \\
\hline
\end{tabular}

(3) Usefulness/necessity

\begin{tabular}{|c|c|c|c|c|c|c|}
\hline & \multicolumn{4}{|c|}{ Before the Fukushima Accident } & \multicolumn{2}{|c|}{ After the Accident } \\
\hline & First & Second & Third & Fourth & Fifth & Sixth \\
\hline Mean & -0.73 & -0.64 & -0.60 & -0.77 & -0.17 & -0.16 \\
\hline $\begin{array}{l}\text { Unbiased } \\
\text { variance }\end{array}$ & 0.82 & 0.79 & 0.88 & 0.75 & 1.29 & 1.33 \\
\hline
\end{tabular}

(4) Safety/anxiety

\begin{tabular}{|c|c|c|c|c|c|c|}
\hline & \multicolumn{4}{|c|}{ Before the Fukushima Accident } & \multicolumn{2}{|c|}{ After the Accident } \\
\hline & First & Second & Third & Fourth & Fifth & Sixth \\
\hline Mean & 0.53 & 0.43 & 0.46 & 0.40 & 1.00 & 1.01 \\
\hline $\begin{array}{l}\text { Unbiased } \\
\text { variance }\end{array}$ & 0.94 & 0.95 & 0.81 & 0.89 & 0.83 & 0.80 \\
\hline
\end{tabular}


after the accident. Significant changes from positive to negative were also seen in relation to Promotion. Also, the changes in unbiased variances showed that, although the variation in attitudes was becoming less (meaning neutral attitudes increased and strong negative/positive attitudes decreased) before the Fukushima Accident, this variation became more pronounced after the accident (meaning neutral attitudes increased and negative attitudes decreased). The mean of Safety, which was a positive value reflecting a tendency towards anxiety, increased because of the Fukushima Accident and demonstrated that there was a tendency towards higher levels of anxiety. There was only a negligible change in unbiased variances before and after the accident, indicating that there was no significant change in variance in attitudes.

Table 8 shows the results of statistically tested changes (expressed as the mean value). Before the Fukushima Accident, the means of Promotion and Usefulness declined significantly between the third and fourth surveys. It shows that prior to the accident, people were positive about using nuclear power and strongly agreed that nuclear power was useful. All question items changed significantly before and after the accident.

There were no significant changes between the fifth and sixth surveys and the changes that did occur seem to be the result of the Fukushima Accident.

c) Summary of analysis and evaluation of the survey results around the time of the Fukushima Accident

A description of the changes between the fourth survey conducted immediately before the Fukushima Accident and the fifth survey conducted after the accident follows. The survey analysis ${ }^{13)}$ performed by Shinoda and others revealed that the evaluations of the strength of positive and negative answers and neutral answers are important and, in this study, each answer option was examined carefully.

(1) Interest: Respondents' interest increased. Option (A) increased by approximately $20 \%$ and option (D) decreased by approximately $15 \%$. The variation in interest decreased.

(2) Promotion: The mean shifted from positive to negative. Option (E) increased by $20 \%$ and option (C) decreased. The variation in this attitude increased.

(3) Usefulness: Fewer respondents came to feel that nuclear power was useful, but no respondents thought it had no utility at all. Both options (A) and (B) decreased by approximately $10 \%$ and options (D) and (E) increased by approximately $10 \%$. No change was observed in option (C). The variation in this attitude increased.

(4) Safety: The tendency to be anxious was further accentuated. The mean of option (A) had been low since before the accident and hardly changed. The means of options (B) and (C) decreased. That of option (D) did not change and that of option (E) increased by approximately $25 \%$. The changes in variation in the attitude to safety were small.

The changes in unbiased variances were due to the distribution leaning towards positive

Table 8 Changes in means based on scores assigned to answer options

\begin{tabular}{cccccc}
\hline & $\begin{array}{c}\text { First } \\
\downarrow \\
\text { Second }\end{array}$ & $\begin{array}{c}\text { Second } \\
\downarrow \\
\text { Third }\end{array}$ & $\begin{array}{c}\text { Third } \\
\downarrow \\
\text { Fourth }\end{array}$ & $\begin{array}{c}\text { Fourth } \\
\downarrow \text { Accident } \\
\text { Fifth }\end{array}$ & $\begin{array}{c}\text { Fifth } \\
\downarrow \\
\text { Sixth }\end{array}$ \\
\hline Level of interest & & & -- & \\
\hline Need to promote nuclear power & & & - & ++ \\
\hline Usefulness/necessity & & -- & ++ \\
\hline Safety/ anxiety & & & ++ \\
\hline
\end{tabular}

Welch's t-test for changes in means

$++(--)$ : Increase (decrease) with $99 \%$ confidence

$+(-)$ : Increase (decrease) with $95 \%$ confidence 
responses, options (A) and (B) (=I am interested) for Interest, wide distribution with decreased weak positive responses, option (B) for Promotion and Usefulness, and the whole distribution shift in a negative direction for Safety. It can be assumed that more respondents who initially had a neutral response to the statement about safety, started responding more negatively.

Only the number of those who chose option (B) for Interest increased significantly following the Fukushima Accident, which indicates that the changes due to the accident are likely to increase even further. No significant change was seen in other options and means, which suggests the changes that appear to be due to the Fukushima Accident have not yet returned to their previous status. This trend does not coincide with the evaluation ${ }^{10)}$ conducted and summarized by the Japan Atomic Energy Relations Organization, which concluded that the objection to the use of nuclear power would decrease and shift towards a neutral attitude. On the other hand, it conformed to the evaluation conducted by Hirose ${ }^{14)}$, who found a continuing negative trend after the Fukushima Accident.

In July 2007, between the first and second surveys, the Niigata Chuetsu-oki Earthquake (hereinafter referred to as the Chuetsu-oki Earthquake) occurred, followed by a fire in a transformer at the Kashiwazaki Kariwa Nuclear Power Plant Unit 3, all of which were widely reported in the media including the publication of aerial photos. Although the impact of the earthquake is not prominently reflected in the analysis results for Interest and Promotion, the responses rate for Safety slightly increased. We can assume that changes in attitudes/awareness occurred due to the size of the earthquake and post-earthquake status.

(b) Analysis and evaluation of relations

a) Analysis and evaluation of correlation coefficients

First, to understand the relation between the four question items (Interest, Promotion, Usefulness, and Safety), we performed correlation analysis based on the numerical information obtained by assigning scores to answer options. Figure 3 shows the changes in correlation coefficients between each question item over time. The error bars in the graphs indicate the $99 \%$ confidence interval of the correlation coefficients. Table 9 shows the statistically tested results of the differences (changes) in correlation coefficients. The changes between the fourth and fifth surveys are assumed to be due to the impact of the Fukushima Accident. Changes before the
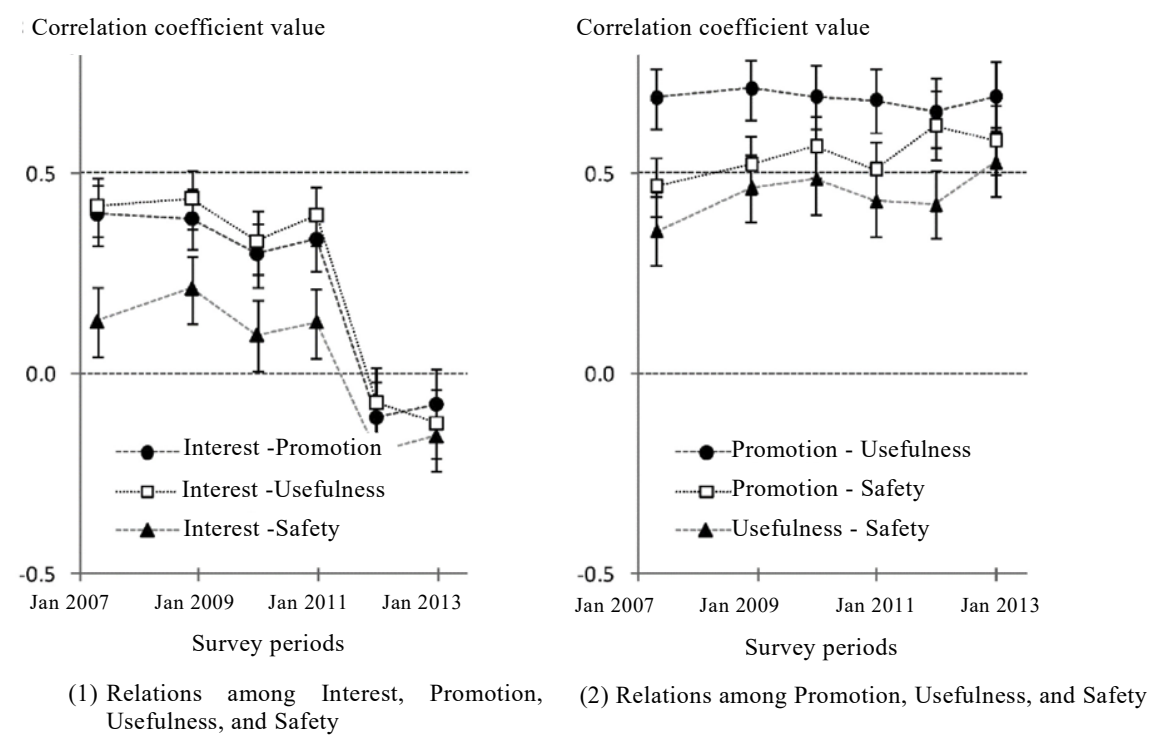

Figure 3 Changes in correlation coefficients between question items over time 
Table 9 Differences in correlation coefficients between question items

\begin{tabular}{cccccc}
\hline & $\begin{array}{c}\text { First } \\
\downarrow \\
\text { Second }\end{array}$ & $\begin{array}{c}\text { Second } \\
\downarrow \\
\text { Third }\end{array}$ & $\begin{array}{c}\text { Third } \\
\downarrow \\
\text { Fourth }\end{array}$ & $\begin{array}{c}\text { Fourth } \\
\downarrow \text { Accident } \\
\text { Fifth }\end{array}$ & $\begin{array}{c}\text { Fifth } \\
\downarrow \\
\text { Sixth }\end{array}$ \\
\hline Interest-Promotion & & & $* *$ & \\
\hline Interest-Usefulness & & $*$ & $* *$ \\
\hline Interest-Safety & & & $*$ \\
\hline Promotion-Usefulness & & & $*$ \\
\hline Promotion-Safety & $*$ & & $*$ \\
\hline Usefulness-Safety & & & \\
\hline
\end{tabular}

Test for differences in correlation coefficients

$* *(*)$ : Significant with $99 \%(95 \%)$ confidence

accident are small. Changes between the fifth and sixth surveys, which were conducted one and two years after the accident, are not significant except for the categories Usefulness and Safety.

In Figure 3 (1), which shows changes in relation to Interest, over time, there were changes from positive to negative correlations around the time of the Fukushima Accident in relation to Promotion, Usefulness and Safety. After the Fukushima Accident, the correlation coefficients between Interest and Usefulness $(\square)$ in the fifth survey and those between Interest and Promotion (๑) in the sixth survey are not statistically significant and their relationship is lost. Other relationships have statistically significant correlation coefficients and are related to each other.

In Figure 3 (2), which shows changes in the relations among Promotion, Usefulness, and Safety, correlation coefficients are significant throughout all surveys and all are related. The relation between Promotion and Usefulness $(\bullet)$ is especially strong and maintains a constant level throughout all surveys. Only the correlation coefficient between Promotion and Safety $(\square)$ around the time of the Fukushima Accident and those between Usefulness and Safety ( $(\mathbf{\Delta})$ after the accident show a significant increase.

b) Analysis and evaluation of partial correlation coefficients

It is hard to evaluate relations simply by means of correlation coefficients when the relations between question items are complex. As for relations between multiple question items that are related to each other, relations between only question items can be found by obtaining partial correlation coefficients. Figure 4 describes the changes in partial correlation coefficients over time.

The partial correlation coefficients between Interest and Safety (A) shown in Figure 4 (1) were negative across all the surveys and the level of interest and strength of concerns were related. The values were close to zero in the first, second, and fourth surveys; no statistical relations were observed and there was no significant relation before the Fukushima Accident. However, significant relations were evident in the fifth and sixth surveys after the accident. The changes in the relation between Interest and Usefulness $(\square)$ were significant after the Fukushima Accident and it continues to increase afterward. Although the level of interest in nuclear power and the degree to which the public saw nuclear power as useful tended to be related before the Fukushima Accident, the relation was lost and started to reverse after the accident. The relation between Interest and Promotion ( ) was lost after the Fukushima Accident, which shows that there was a change in the level of public interest.

The partial correlation coefficient values between Promotion, Usefulness, and Safety, shown in Figure 4 (2), are mostly significant and relations are observed between the question items. However, the partial correlation coefficient values between Usefulness and Safety $(\boldsymbol{\Delta})$ in the first and fifth surveys are not significant.

Another prominent feature is that the relation between Promotion and Usefulness 


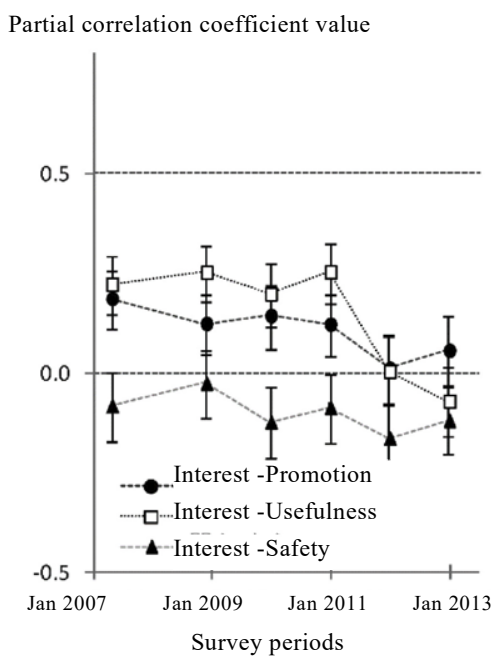

(1) Relations among Interest, Promotion, Usefulness, and Safety

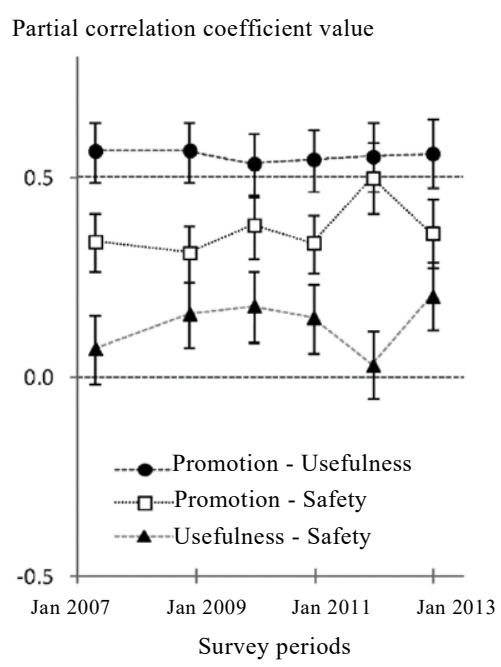

(2) Relations among Promotion, Usefulness, and Safety

Figure 4 Changes in partial correlation coefficients between question items over time

maintains a certain level throughout all the surveys and Need to promote nuclear power and Usefulness/necessity are strongly related. Around the time of the Fukushima Accident, the relations between Promotion and Safety $(\square)$ and Usefulness and Safety increased and then decreased. However, as for the changes over time in the fifth and six surveys after the accident, the changes in relations due to the Fukushima Accident returned to the statuses before the accident. The feeling of safety increased slightly around the time of the Chuetsu-oki Earthquake and the correlation between Usefulness and Safety became strong, which indicates a change in awareness and attitudes caused by the earthquake.

(c) Analysis and evaluation by principal component analysis (PCA)

PCA is a statistical method used to extract common components from multidimensional observed variables (actually measured variables; here they refer to survey results) and newly obtained non-correlated composite variables. The extracted components are called principal components. They are ranked in the order of how well they account for (contribution rate) all the information included in question items. The loads of principal components are between -1 and 1 and indicate the impact (weight) of observed variables against the principal components. Because the sum of the observed variables multiplied by the loads of principal components is principal components (composite variables), it allows us to establish a new standard where information is condensed and explore the structure of observed variable groups. This analysis allows us to deepen the above stated correlation analysis further. PCA is formulated as follows and principal components are represented by observed variables.

jth principal component

$=($ Load of the jth principal component of observed variable 1$)$

$\times($ Observed variable 1$)$

+ (Load of the jth principal component of observed variable 2$)$

$\times$ (observed variable 2$)$

$+($ Load of the jth principal component of observed variable $\mathrm{N})$

$\times($ Observed variable $\mathrm{N})$ 
$\mathrm{jth}$ Principal component ( $\mathrm{j}=1 \sim \mathrm{L}: \mathrm{L}$ matches the number $\mathrm{N}$ of observed variables at most)

a) Promotion, usefulness and safety of nuclear power

First, for three question items (Promotion, Usefulness and Safety) we performed analysis using the numerical information obtained by assigning scores to answer options. The number of observed variables becomes $\mathrm{N}=3$. Figure 5 shows the changes over time in the loads and contribution rates of the first to third principal components.

For the first principal component for which the contribution rate is the largest at approximately $70 \%$ throughout all the surveys, the three question items line up in the same direction. It means the three question items move in the same positive/negative directions and this connects the attitude of being "positive about promotion/usefulness/safe" and the attitude of being "negative about promotion/unnecessary/anxious". These variables indicate the public's attitude (for or against) to nuclear power by representing their feelings either for or against its use. The responses to questions about Promotion, Usefulness, and Safety account for approximately $70 \%$ of the public's attitude (for/against) to nuclear power; the load of the principal component for Safety decreased after the Fukushima Accident.

The second principal component shows an approximately $20 \%$ contribution rate, where Usefulness and Safety move in opposite directions in all the surveys. The direction of Promotion is reversed and moves in the same direction as Safety around the time of the Fukushima Accident. As for the second principal component, the attitude to the promotion of nuclear power does not directly reflect the feeling of being either for or against it. The second principal component represents a dissociation between the attitude to promotion and the feeling of being for or against nuclear power per se. We can see that the second principal component is a variable that represents the conflict between usefulness and anxiety and indicates ambiguity (in people's stances). From this perspective, although people were anxious before the Fukushima Accident, their attitude regarding the usefulness of nuclear power was linked to their attitude regarding its promotion.

However, after the accident, people's anxiety resulted in an increasingly negative attitude

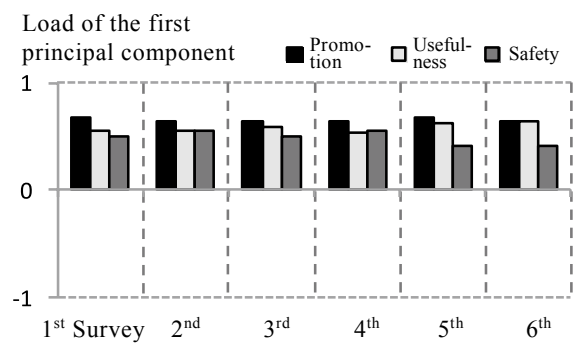

(1) Load of the first principal component

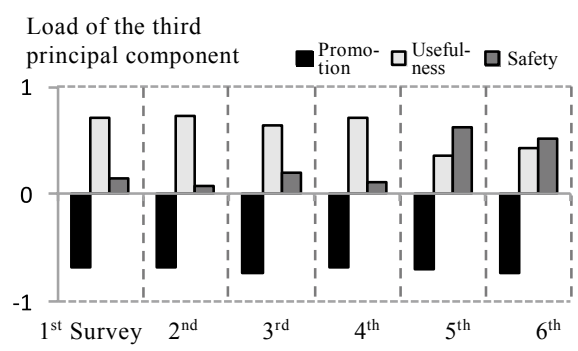

(3) Load of the first principal component

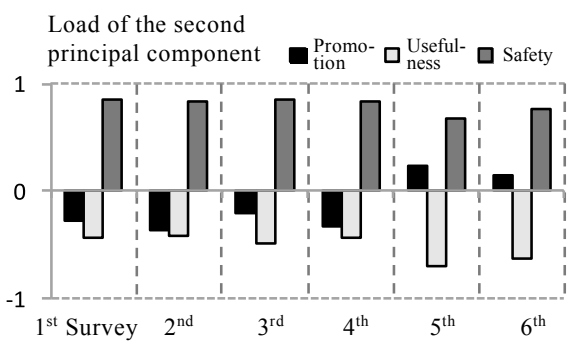

(2) Load of the first principal component

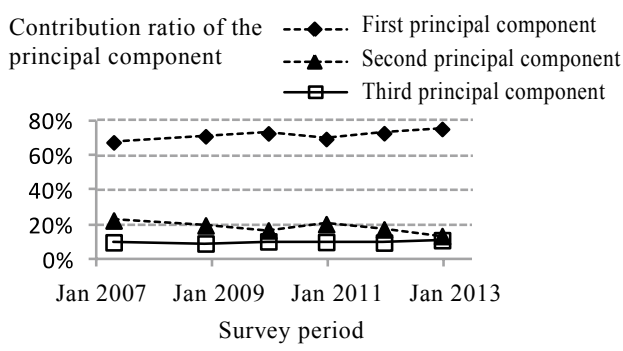

(4) Changes in contribution ratio over time

Figure 5 Principal component analysis results between three question items (based on load of principal component and contribution rate) 
toward the promotion of nuclear power. This is a reversal of the attitude that they would like to "promote nuclear power because it is useful although we have concerns" to they would like to "phase out nuclear power because it is not safe, even if it is useful". The contribution rate decreased after the accident and accompanied by a declining trend is seen in people's recognition of ambiguity. The decline in ambiguity is in response to a strengthening of the relations among "perception of usefulness/uselessness", "feeling of safety/anxiety towards nuclear power", and "need to promote nuclear power".

The third principal component has a less than $10 \%$ contribution rate, where Promotion and Usefulness and Safety move in opposite directions. Although Usefulness was assigned a high value and Safety a low value before the Fukushima Accident, they have both increased in the same direction following the accident. The first principal component shows that the awareness structure is directly linked to the attitude of being for or against the use of nuclear power; "As I think nuclear power is useful and safe and I would like the government to use it, therefore I am for = positive about nuclear power" or "I think the use of nuclear power is dangerous and I feel anxious and I would like the government to stop using it, therefore I am against = negative about nuclear power". It also shows that the perception of usefulness (necessity) and feelings of safety (anxiety) have become the major determining factors of the attitude (for or against) to the use of nuclear power. On the other hand, the third principal component shows an awareness structure that reflects the following attitude to nuclear power; "Although I think nuclear power is useful and safe, I am opposed to its use" or "Although I think nuclear power is dangerous and I feel anxious, I support its use", which are clearly contradictory and they cannot be understood in a logical manner. We can assume that it also suggests that other determining factors have had an impact.

b) Interest in and promotion, usefulness, and safety of nuclear energy

Next, we performed a similar analysis adding Interest into the question items; the results are shown in Figure 6. The impact of interest was evident in the first principal component, which

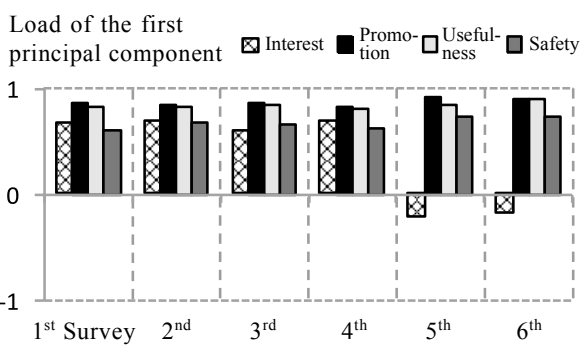

(1) Load of the first principal component

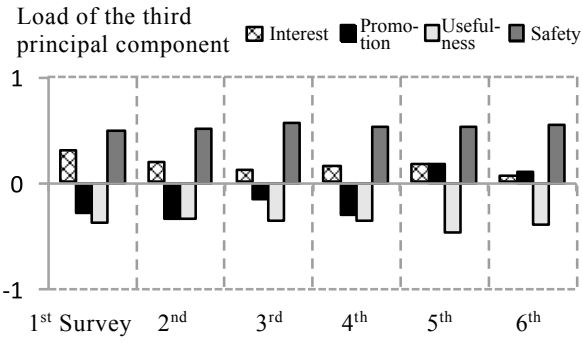

(3) Load of the third principal component

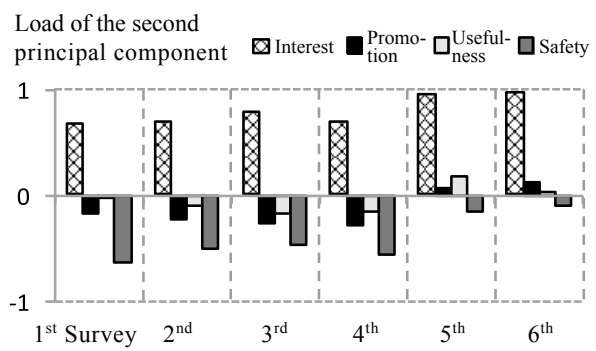

(2) Load of the second principal component

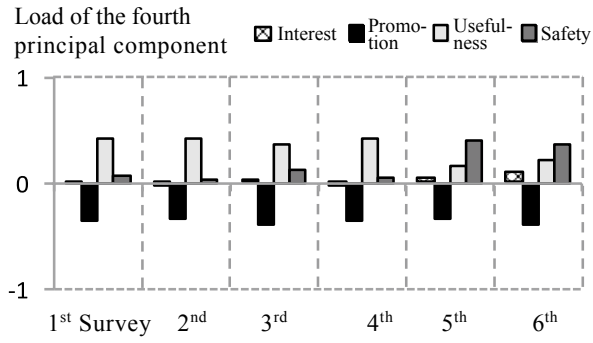

(4) Load of the fourth principal component

Figure 6 Analysis results of principal components between four question items (load of principal component) 
reflects the attitude of being either for or against the use of nuclear power. The four question items were oriented in the same direction before the Fukushima Accident, but the direction of Interest was reversed with small values after the accident. This reversal indicates that the relation between the attitude of being for or against nuclear power and the level of interest in nuclear power observed before the Fukushima Accident became weak after the accident. The growing interest after the accident indicates that people's interest is no longer related to whether they are for or against nuclear power and it supplements the analysis results by partial correlation coefficients.

In the second principal component, Interest received high scores in all the surveys. The scores are values that indicate the strength of public interest in nuclear power without factoring in the impact of being either for or against it as indicated by the first principal component. Before the Fukushima Accident only Interest was oriented in a direction opposite to that of the other question items. The values for Interest and Safety are higher than those of the others; thus, it can be concluded that anxiety leads to interest. Scores other than those for Interest decreased and only Safety was oriented in the opposite direction and registered low scores after the Fukushima Accident. This indicates that interest led by anxiety, regardless of respondent's attitude towards nuclear power, became low after the accident.

The pattern of the third principal component was similar to that of the second principal component based on an analysis of the three question items. Both Interest and Safety were oriented in the same direction and registered low scores. The pattern of the fourth principal component was similar to that of the third principal component based on an analysis of the three question items.

(d) Analysis and evaluation by quantification method III

Quantification method III enabled analysis even though it was not an interval scale and captured the relations between answer options and respondents. It calculated several axes that categorized options' features and that were not related to each other based on the relations of response, and provided scores that represented the features of each axis.

In the previous reports released by the Institute of Nuclear Safety System, Incorporated ${ }^{7)}$ and Shinoda ${ }^{13)}$, quantification method III was used to analyze attitudes regarding the use of nuclear power and interesting findings were obtained. As with principal component analysis, the axes were ranked in the order of how well they accounted for (contribution rate) all the information included in the question items.

Quantification method III is different from principal component analysis in that it analyzes without assigning scores. Compared to the PCA, in quantification method III, the contribution rates of calculated variables were relatively low, and interpretation of results is difficult. However, it provides information for multiple answer options. Exploring the relations between answer options allows the study of the respondents'.

First, three question items were analyzed (Promotion, Usefulness, and Safety). If options scores are plotted on a plane having two axes with high contribution rates, the trends (statistically similar tendency of trends) in the responses to questions can be captured. The contribution rates of the first and second axes were approximately $20 \%$ and $15 \%$, respectively.

Figure 7 shows the results of the third survey before the Fukushima Accident and fourth survey shows the results after the accident, which represent the features of the results around the time of the Fukushima Accident. The letters $\mathrm{P}, \mathrm{U}$, and $\mathrm{S}$ respectively represent the question items Promotion, Usefulness, and Safety and A to E represent the answer options (A) to (E) in Tables 3 to 5. The first axis represents public attitudes (for or against) to nuclear power and all three question items are ranked in the order of the strength of the attitude for or against nuclear power. $\mathrm{A}$ and $\mathrm{E}$, in the second axis, which show strongly positive and negative responses, 


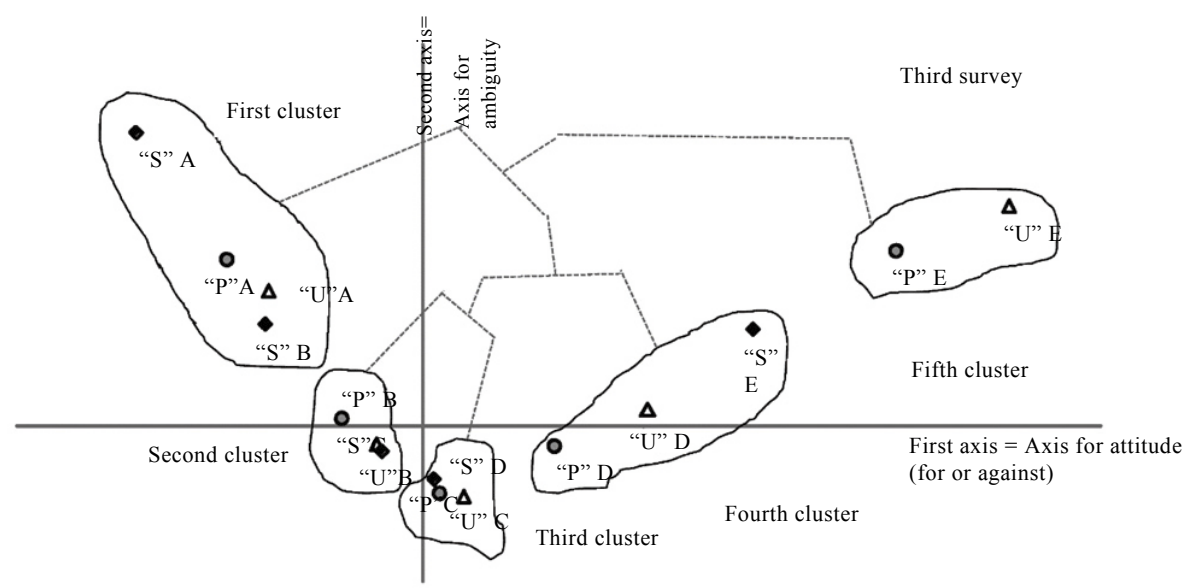

(1) Third survey (Before the Fukushima Accident)

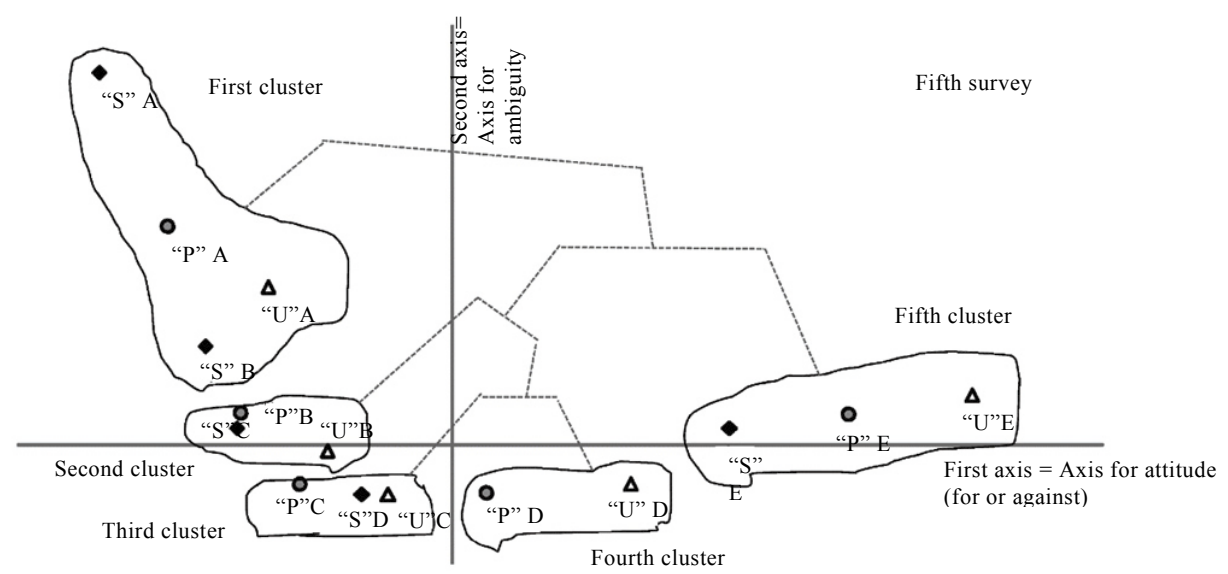

(2) Fifth survey (After Fukushi ma Accident)

Figure 7 Results of the analysis between question items by quantification method III (First and Second axes plane)

indicate the strength of opinions and number of opinions along it and the axis can be regarded as representing awareness of ambiguity. The first axis indicates respondents' attitudes to the use of nuclear power (for or against) and the second axis indicates a sense of ambiguity and these reflect the same trend that was seen in PCA.

If cluster analysis is performed on the relations between answer options plotted on the graph, the differences before and after the Fukushima Accident become clear. In cluster analysis, the target numerical value group is divided into "subsets = cluster", (which achieve internal connections and external separation). Using the option score distribution obtained by quantification method III, the option groups that are likely to be chosen by a respondent can be identified simultaneously.

We used Ward's method (Euclidean distance) for phased clustering and determined the division number and cluster characteristics by dendrogram, which represent the process through which individual data is aggregated.

In Figure 7, solid curved lines indicate clusters of several answer options placed based on 
the analysis results and dotted lines connect these clusters. Before and after the Fukushima Accident, we can observe differences in the connections between options (B), (C) and (D), which indicate weak positive, negative and neutral opinions respectively. Before the accident, the fifth cluster, which aggregates options reflecting strong negative opinions, was connected to another last. However, after the accident, the first cluster, which aggregates options reflecting strong positive opinions, is connected to another last. Getting connected to another cluster last indicates that the options in the cluster are most isolated, which means the attitudes of the respondents who chose the options in the cluster are most isolated from those of other survey audiences.

Shinoda ${ }^{12)}$ analyzed the backgrounds of those who tend to choose neutral answers, options (B), (C), and (D), using quantification method III and demonstrated that the public's stance or disposition can be understood by finding out whether the neutral group agrees with/feels empathy towards a group with strong positive opinions or a group with strong negative opinions. Such a neutral group accounts for the majority of respondents. The analysis results shown in Figure 7 indicate that the neutral group gradually came to adopt a favorable stance by creating the group with positive opinions before the Fukushima Accident, but this stance was reversed (into opposition) after the accident.

The orientation of each option did not significantly differ before and after the Fukushima Accident, but the orientation of the cluster of options indicating neutral opinions (third cluster) changed. We can find the features of the options from this orientation. Figure 8 shows the changes over time in distinctive values of the first axis, which shows the public attitude (for or against) to nuclear power. The attitudes of those who chose option (C) for Promotion and Usefulness in Figure 8 (1) included negative opinions before the Fukushima Accident, but which shifted to positive after the accident.

In Figure $8(2)$ the values $(\diamond)$ of option $(C)$ are in the positive direction throughout all the surveys for Safety and they further inclined in the positive direction after the Fukushima Accident. The values $(\boldsymbol{\Delta})$ of option (D) shifted directions (for or against) after the accident. People tend to avoid clearly stating their opinion by choosing options such as "Neither" because they sense the prevailing public sentiment at the time and only weakly oppose it. Respondents' choice of option (C), in other words avoiding making a clear indication of their opinion, depends on the degree to which they sense the social sentiment at the time. Respondents' choice of option (D), which is weak opposition, regarding Safety after the Fukushima Accident means "they do not utterly reject concerns about safety" and that they feel somewhat positive about the promotion of nuclear power.

When an evaluation is made together with the changes in survey responses around the time of the Fukushima Accident as indicated in Table 6, it is observed that people's shift from option (C) for Promotion from negative to positive around the time of the Fukushima Accident represents an alteration in their perception of social sentiment. We can see that the rejection of the promotion nuclear power became the prevailing social atmosphere after the accident. Also, we can assume that the unchanged response rate for option $(\mathrm{C})$ for Usefulness indicates that it is harder for people to decide whether nuclear energy is useful or unnecessary compared to deciding if nuclear power should be promoted or not.

When we analyze the three question items as well as Interest using quantification method III, we can see that before the Fukushima Accident, "Level of Interest (degree)" and "attitude (for or against) to nuclear power" faced in the same direction along the horseshoe-shaped distribution shown in Figure 7 (1), which means interest and attitude (for or against) were related in the same direction, along with an ambiguous stance as indicated by the second axis. On the other hand, after the accident the distribution of the options selected for Interest changed; the value 


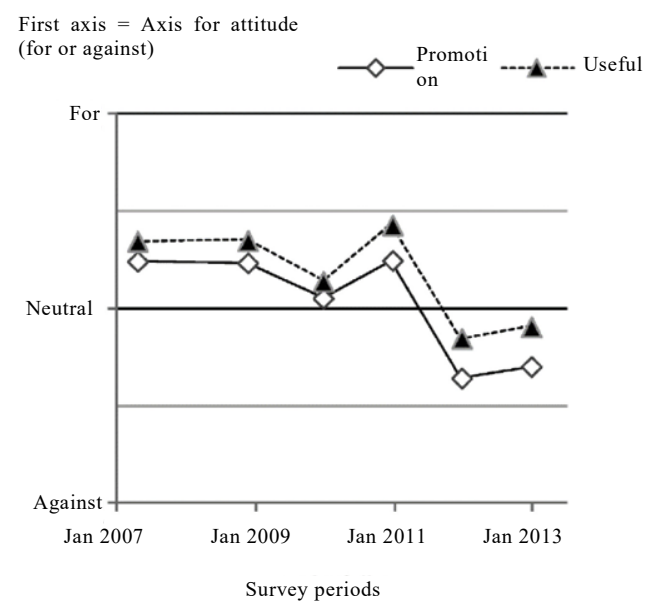

(1) Changes over time in the response rate for option (C) "Neither" question items Promotion and Useful on the first axis (Axis representing attitude (for or against))

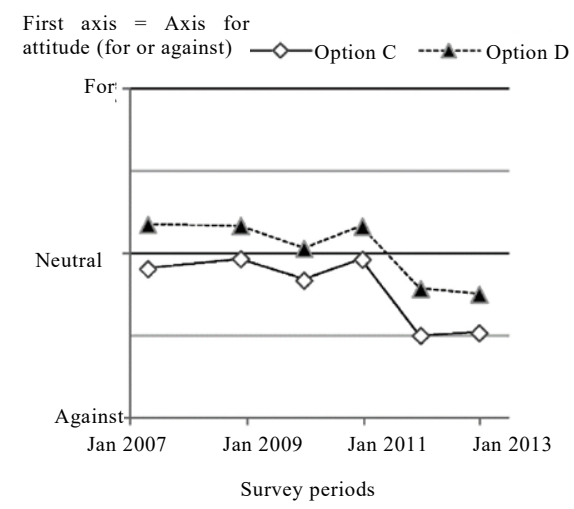

(2) Changes over time in the response rate for option (C) "Neither" option (D) "I feel somewhat anxious" for question item Safety ol the first axis (Axis representing attitude (for or against))

Figure 8 Changes over time in analysis results between question items using quantification method III (First axis $=($ Axis representing attitude (for or against $))$

for the first axis, which indicates the attitude (for or against) to nuclear power, became nearly zero and only option (A) for Interest had a high value on the second axis.

Regardless of the attitude (for or against) to nuclear power, we can see from this analysis that a high level of awareness of nuclear power among the public and the strength of their interest are related.

\section{(2) Analysis and evaluation of respondents' levels of agreement based on their opinions on the use of nuclear power}

In this question, as the response rate for option (F) "I don't know" was high, an evaluation was conducted by assigning scores to options. One of the factors that has a large impact on the attitude (for or against) to nuclear power is trust. We can gauge this impact through the question in this section concerning trust in those who are engaged in the generation of nuclear power. As we focus on changes before and after Fukushima Accident, the responses to Risk of earthquake 
are also covered in this section.

Table 10 shows the results of a statistical test on the changes over time in the response rates for Trust and Risk of earthquake. Regarding the latter, the rate for option (A), which represents an affirmative response to the question regarding the risk, increased around the time of the two earthquakes. Before and after the Chuetsu-oki Earthquake, the changes in response rates for options other than option (A) were not significant. The response rate for option (A) changed after the Chuetsu-oki Earthquake and gradually shifted back later. Around the time of the Fukushima Accident, there was a significant decrease in the selection of options (B), (C), and (F), and we can see that people chose option (A) due to an increased awareness of the risk posed by earthquakes. Although we cannot ascertain attitudes and awareness before 2007, as far as the present study is concerned, significant changes occurred after the Fukushima Accident. To be more specific, vague awareness of issues related to nuclear power changed into firm convictions; for example, people became increasingly convinced that a nuclear power plant accident caused by an earthquake would lead to serious damage. The most significant change in this attitude occurred after the Fukushima Accident. The response rates for options (D) and (E), which represent a rejection of the notion that earthquakes are a risk, were low and remained the same before and after the earthquake.

From the Trust perspective, the change trends vary between the two earthquakes. It significantly increased around the time of the Chuetsu-oki Earthquake and then gradually increased until before the Fukushima Accident. Considering this together with the changes in responses to Safety, it is assumed that the impact of the Chuetsu-oki Earthquake and the actions taken in response to it were viewed favorably. From the changes over time in the response rates as shown in Figure 1, it can be seen that the response rate for option (B), which represents trust, increased and those for options (D) and (E), which represent a negative trend, decreased between the Chuetsu-oki Earthquake and the Fukushima Accident. In the fourth survey, the "trusting" group that chose options (A) and (B) increased to its highest level at $44.2 \%$ and the "distrusting" group that chose options (D) and (E) decreased to its lowest level at 12.2\%. These results suggest that there was no outstanding change in status during this period and the smooth operation of nuclear power plants increased the level of public trust.

However, trust decreased after the Fukushima Accident. The change was not particularly significant, and the level of trust increased up until before the accident and then declined back to a level close to that in 2007 , when this study was initiated. It did not change markedly after the accident compared to "risk of earthquake". The trust built up in many people who never imagined that a nuclear power plant accident would occur before the Fukushima Accident was lost due to the impact of the accident. However, when we evaluate impact on trust, it is

Table 10 Test results of changes in response rates

(1) "Trust"

\begin{tabular}{cccccc}
\hline $\begin{array}{c}\text { Test of } \\
\text { significant } \\
\text { differences in } \\
\text { response rate } \\
\text { changes }\end{array}$ & $\begin{array}{c}\text { First } \\
\text { Second }\end{array}$ & $\begin{array}{c}\text { Second } \\
\downarrow\end{array}$ & $\begin{array}{c}\text { Third } \\
\downarrow\end{array}$ & $\begin{array}{c}\text { Fourth } \\
\text { Thecident } \\
\text { Fourth }\end{array}$ & $\begin{array}{c}\text { Fifth } \\
\text { Fifth } \\
\text { Sixth }\end{array}$ \\
\hline (A) & + & & & \\
\hline (B) & ++ & + & -- \\
\hline (C) & & & \\
\hline (D) & -- & & ++ \\
\hline (E) & -- & & ++ \\
\hline
\end{tabular}

(F)
(2) "Risk of earthquake"

\begin{tabular}{cccccc}
\hline $\begin{array}{c}\text { Test of } \\
\text { significant } \\
\text { differences in } \\
\text { response rate } \\
\text { changes }\end{array}$ & $\begin{array}{c}\text { First } \\
\downarrow \\
\text { Second }\end{array}$ & $\begin{array}{c}\text { Second } \\
\downarrow \\
\text { Third }\end{array}$ & $\begin{array}{c}\text { Third } \\
\downarrow \\
\text { Fourth }\end{array}$ & $\begin{array}{c}\text { Fourth } \\
\text { Accident } \\
\text { Fifth }\end{array}$ & $\begin{array}{c}\text { Fifth } \\
\downarrow \\
\text { Sixth }\end{array}$ \\
\hline (A) & ++ & & & ++ & \\
\hline (B) & & & -- & \\
\hline (C) & & & -- & \\
\hline (D) & & & & \\
\hline (E) & & & \\
\hline (F) & & & -- \\
\hline
\end{tabular}

$++(--)$ : Increase (decrease) with $99 \%$ confidence, $+(-)$ : Increase (decrease) with $95 \%$ confidence 
important to take into account the subject upon which trust was evaluated. In this study, the subject was "safety ensured by those who are engaged in the generation of nuclear power". Further study is required regarding trust.

(3) Analysis and evaluation of matters respondents are interested in and/or are concerned about in daily life

In this question, about 20 matters were presented as answer options. Most of the matters in which respondents have an interest in and/or anxiety about tend to be similar. Some of the matters in this question sensitively reflect the social situations at that time. For example, people's interest in and concerns about imported food, shown in Figure 2, significantly increased between the first and second surveys. We can say that this was due to the impact of the Chinese toxic dumplings incident in January 2008. A year later, the values returned to nearly the same levels as those before the incident. Each matter has their own specific features; for example, the number of selections was highest for Sickness throughout all the surveys and shows a stable trend.

The matters presented include Nuclear power and Nuclear-related accident. The former evokes a vaguer image of nuclear power in general, while the latter refers to a more specific topic with the addition of the word "accident".

The numbers of selections for "interest in" and "concerns about" for both matters significantly increased around the time of the Fukushima Accident. The increment for "Nuclear-related accident" is higher than for "Nuclear power" after the Fukushima Accident, and we can assume that this can be attributed to the impact of the accident. The concerns about "Nuclear-related accident" significantly decreased in the fifth and sixth surveys after the accident. However, this decrease needs to be examined in light of the next survey (scheduled to be conducted in January 2014).

In this study, interest in and concerns about nuclear power have already been covered by the question II-2-(1) in the section "Interest and concerns" for which five answer options were provided. It could be assumed that the results for the two questions would be different; one is a question that asks respondents to select an option corresponding to their interest in and concerns about nuclear power in relation to several specific topics including Sickness and Natural disaster and another is a direct question that asks about their "interests and concerns" by specifying these in the question. Providing these two types of questions in a survey allows us to see the influence of being conscious of interest and concerns by explicit representation.

Figure 9 (1) shows the changes over time in the response rates of those who chose both Nuclear power and Nuclear-related accident $(\boldsymbol{\Delta})$, Nuclear power only $(\bullet)$, Nuclear-related accident only $(\boldsymbol{\square})$ and at least one of them in a question regarding respondents' interest in Nuclear power and Nuclear-related accident. Figure 9 (2) shows the response rates of the same respondents in a question about concern. The response rate of those who chose at least one of those matters $(\bigcirc)$ is the same rate as those who expressed whether they are interested in/concerned about nuclear power in response to the questions about interest and concerns.

Figure 10 shows the changes over time in interest $(\bigcirc)$ and concerns $(\diamond)$ depicted in Figure 9 by adding "matters selected". In this figure we added the sum of the response rates for options (A) and (B) as (-), which represents the rate of respondents who expressed interest, for the question item Interest in the question mentioned in Section II-2-(1) and the sum of those for option (D) and (E) as $(\bullet)$, which represents the rate of respondents with concerns, for the question item Safety, as an "explicit question". We categorized respondents based on whether they are interested in and/or concerned about nuclear power, but disregarded the strength of that interest and concerns. 


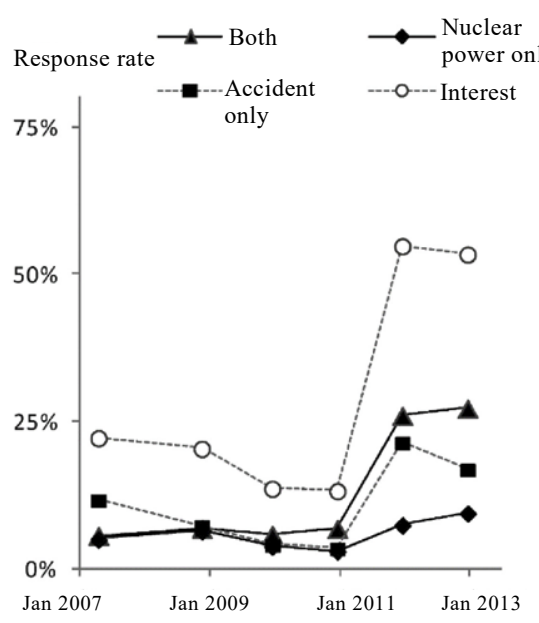

Survey periods

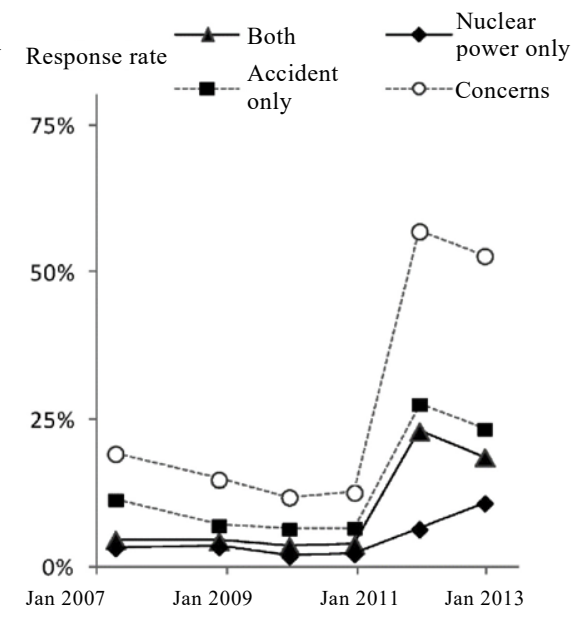

Survey periods

(2)Concerns

(1)Interest

$\boldsymbol{\Delta}$ : Both— Rate of respondents who chose both "Nuclear power" and "Nuclear-related facility accident"

•: Nuclear only— Rate of respondents who chose "Nuclear power" only

a: Accident only—Rate of respondents who chose "Nuclear facility accident" only

○: At least one of them— Rate of respondents who chose both or one of either "Nuclear power" or "Nuclear facility accident"

Figure 9 Changes over time in the response rates for interest in and concerns about nuclear power

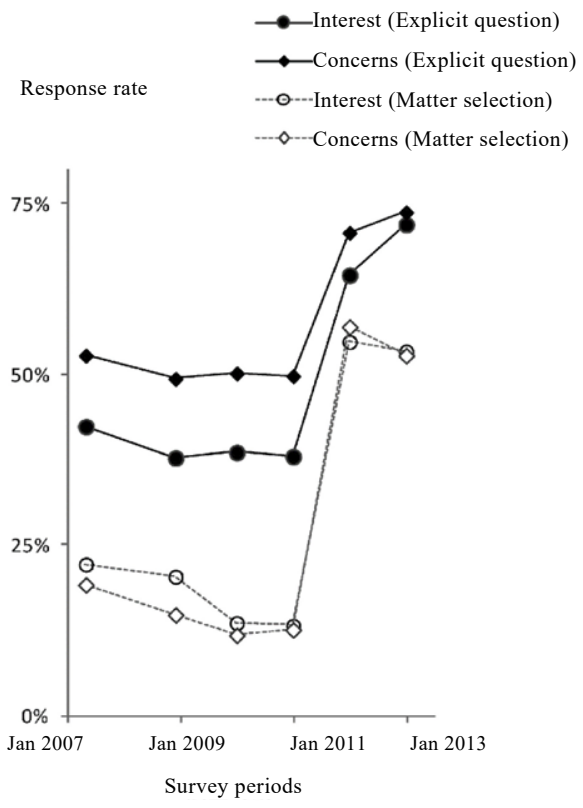

Figure 10 Differences between the results of two types of questions regarding interest in and concerns about nuclear power 
Before the Fukushima Accident, there were differences in the results between two different types of questions ("explicit questions" and "matter selection") regarding respondents' interest in and concerns about nuclear. After the accident, although the rate for interest and concerns increased, and the gap between the results for the two questions was narrowed. We can say that it partially captures the feature of interest and concerns led by an increase in awareness of nuclear-related issues. These results suggest that for the survey respondents, who were living in the Tokyo metropolitan area, awareness or concerns about nuclear power-related issues was low before the Fukushima Accident. It is highly likely that some trigger (e.g. the survey in this case) induced them to respond that they had interest in and concerns about nuclear power even if they were not aware of it in everyday life.

It is assumed that they started to become aware of nuclear power in everyday life after the Fukushima Accident. We can say that it narrowed the gap between the results of two types of questions.

\section{Summary of Analysis Results and Discussion}

By using various statistical tools including testing for changes, analysis of relations, principal component analysis, applying quantification method III, and cluster analysis with the changes over time in simple survey results, we attempted to explore the underlying factors of people's awareness of and attitudes to nuclear power, which are difficult to discover based on simple survey results only. For example, about $20 \%$ of respondents chose the same answer options for the question items Promotion, Usefulness, and Safety throughout all the surveys. Although in the early surveys about 10 percent of respondents chose option (C) for all the questions, this percentage gradually decreased at a constant rate in the two years prior to the Fukushima Accident and had decreased to about $4 \%$ in the sixth survey accelerated by the Fukushima Accident. It should not be assumed that the selection of option (C) Neither indicates that the respondent has no opinion, but such respondents started to show their opinions more clearly. At the same time, their hesitation and ambivalence decreased. Many respondents chose different options for each question item. This influence is shown by the statistical analysis used in this study.

By using principal component analysis, we were able to reaffirm that people's attitude (for or against) to nuclear power is determined primarily by opinions regarding whether or not they think nuclear power should be promoted, nuclear energy is either useful or not, and feel safe/ anxious about nuclear power. Also, it showed that their feelings of safety and anxiety have less impact on their attitude (for or against) to nuclear use than the other two question items. The main purpose of the use of principal component analysis is to condense information and conventional analysis rarely refers to principal components with a low contribution rate. In this study, we tried exploring the structures of the question item groups by also taking into account principal components with a low contribution rate and examined the psychologically complex way respondents thought about these matters, such as their perception of usefulness/necessity and feelings of safety and anxiety towards nuclear power. We found that such thinking changed in response to the Fukushima Accident.

We also revealed changes in awareness and attitudes among people in the middle layer (the middle layer in this study refers to the group of people who have neutral opinions that may vary depending on the survey) before and after the accident using quantification method III. To gain a deeper understanding of these changes among people in the middle layer resulting from the Fukushima Accident, we must evaluate respondents from the middle layer whose attitudes changed; for example, those who left the layer and those who moved into the layer. This study is not a follow-up study and we therefore cannot examine the changes over time in the 
responses of individual respondents. We tried exploring the factors underlying the awareness and attitudes of people with neutral opinions although these could be regarded as a limitation of the sample survey.

The study evaluated the impact of the Fukushima Accident based on the changes in people's awareness and attitudes over several years before and after the accident, taking advantage of previous surveys that were conducted at regular intervals. The shift to negative attitudes towards nuclear power generation, which seems to be an impact of the Fukushima Accident, has generally been maintained even though two years have passed since the accident occurred. After the accident, public interest in nuclear power generation has increased and it has become something that the public are aware of in everyday life. People's attitude towards the use of nuclear energy has shifted from positive to negative; they have become less positive about its usefulness, their anxiety has increased, and they have less confidence in nuclear power. There are no strong signs that such attitudinal changes are returning to the status that existed before the Fukushima Accident. This is due to the strong influence of the changes in awareness and attitudes in respondents occupying the middle layer arising from the situation where "nuclear power has become a common component of our daily lives".

In this survey, we confirmed some changes in awareness and attitudes had returned to their previous status after one year or so depending on which factor had been instrumental in changing it (e.g. Chuetsu-oki Earthquake and Chinese toxic dumplings incident). Also, one survey ${ }^{15}$ ) reported that public sentiment having changed due to the accident at the Mihama Unit 3 reverted back to its previous status after about one year. Shinohara ${ }^{12)}$ also reported that based on analysis of the results of a nuclear study conducted by various organizations, no other impact of nuclear accidents and incidents have lasted for a long period with the exception of the impact of the Chernobyl Accident. From the survey results, we can see that the changes in attitudes and awareness have not returned to their previous status and it is clear that the Fukushima Accident had a significant impact on people.

As for changes that seem to have originated from the impact of the Fukushima Accident, how people become interested in nuclear power needs to be noted. This means it is important to explore further how people's interests have increased and how that affects the future use of nuclear power. Our analysis revealed that, before the Fukushima Accident, there was a tendency for an interest in nuclear power to be linked positively to the use of nuclear power and so, too, was lack of interest in nuclear power linked to a negative perception of nuclear power. If we interpret the data to mean that it shows people's hesitation to show a positive attitude to nuclear power even though they are not interested in it or a negative attitude even though they are interested in it, we can say that, based on this psychological tendency, people's interest and attitude (for or against) to nuclear power were linked before the accident.

Such relationships are likely to change depending on external factors. After the accident, those having a high interest in nuclear power tend to show either a very positive attitude or very negative attitude towards it, or we can say that the accident simultaneously evoked a strong negative attitude to and very high interest in nuclear power. This was also demonstrated by the analysis using quantification method III. Public interest in nuclear power appears to be unprecedented. When policies on how nuclear power should be used are formulated, it is desirable to consider how and why people are interested in it.

People have also become less convinced of its usefulness as a result of the accident. Their feelings about its usefulness/necessity contributed to their attitude (for or against) to the use of nuclear energy rather than anxiety and their feelings regarding its safety. This study could not determine if the accident was the trigger that changed people's values and awareness in everyday life and consequently their belief that nuclear-generated power was unnecessary, or if their 
heightened concerns about nuclear power was the trigger for an attitudinal change to stop using nuclear power and consequently their belief that nuclear-generated power was unnecessary in an effort to be consistent with their own attitude. This must be studied in the future.

\section{Suggestions based on the Analysis of the Study Results}

The study examined the features of changes in awareness and attitudes around the time the Fukushima Accident occurred as well as before and after it. It is obvious that the accident has changed people's attitudes towards the use of nuclear power especially in regard to the safety of nuclear power plants. The study showed that a significant number of people became very interested in the use of nuclear energy in the future but became suspicious of it at the same time. Even two years after the accident, the news related to this event (about such as decontamination, leakage of contaminated water, restart of nuclear reactors and the nuclear power free movement) is still continuously reported and it is assumed that interest will not dissipate rapidly. We think it is natural that whenever energy and nuclear-related news is reported in the future, the Fukushima Accident will definitely be discussed. Thus, the public's focus on and interest in nuclear power have increased given the fact that nuclear power has become an inseparable part of daily life. This situation has drastically changed people's interest in and their attitude (for or against) to nuclear use.

The higher their interest becomes, the less dependent the public will be on the government and experts. Having experienced the Fukushima Accident, new initiatives (determination process) will be needed when determining policy related to the trends and status of nuclear power generation. In such a case, it is not reasonable to expect the public to shed their negative attitude by waiting for them to lose interest in this issue and forget that nuclear power is an intrinsic part of daily life; in other words, by waiting for things to "cool down" and "to be forgotten". There were several prominent incidents that strongly raised awareness of nuclear power generation a few years before the Fukushima Accident. The situation where "no incident happened and nothing was reported" lowered our awareness of nuclear energy in daily life and increased our trust in it with our interest remaining low. It would be reasonable to think such a situation will not happen considering how public awareness and attitudes changed after the Fukushima Accident. It is also clearly demonstrated by the responses to the questions in the survey asking about matters of interest and the concerns of respondents and the fact that nuclear power is becoming an integral part of daily life.

However, regarding trust, it must also be borne in mind that trust in nuclear power has not necessarily unprecedentedly declined since the Fukushima Accident. It is not true that trust was completely lost due to the accident; in fact, nuclear power plants were being operated in the past even though the level of trust was the same as that after the accident. However, if we hypothesize that the increase in trust before the accident represents an increase in a positive view of nuclear power, the trust that was subsequently lost is nothing more than the loss of this positive view. Also, when trust in nuclear power is assessed, how nuclear power has become a common part of daily life needs to be taken into account as this represents the degree to which the public are interested in nuclear power.

In such a situation, first, a positive attitude to nuclear power should be rebuilt; trust must be reestablished for this to happen. To achieve that, restoring trust to a level equivalent to that before the Fukushima Accident is one of the prerequisites for recommissioning nuclear power plants. There is no silver bullet that will restore public trust. Under the circumstances where 
trust cannot be established without information, those who are engaged in the nuclear industry must adopt a fair and transparent approach to nuclear-related matters so that the public can clearly see their commitment. Such efforts would be an effective way to rebuild a positive perception of the nuclear industry.

Deliberative polling on energy and environmental choices based on thorough deliberation conducted under the auspices of the Democratic Party of Japan is an exciting initiative. The increased interest in nuclear issues due to the Fukushima Accident was a great opportunity for constructive discussion on the use of nuclear power. Allowing a numerous people who were not proactive in such deliberations before to get involved in such an initiative has had an influence on the awareness and attitudes of people in the middle layer and may lead to a change in the social atmosphere. Citizens' participation in this form of deliberation that ensures representativeness will enhance the image of nuclear energy in the eyes of the public and convert non-participating citizens into active participants in such deliberations. The situation today where nuclear power has become an intrinsic part of our lives can be a tremendous opportunity for the country to explore the future direction of the use of nuclear power together with the participation of forward-thinking citizens. Also, placing importance on discussions with citizens in the decision-making process when formulating nuclear strategies is an essential element to ensure fairness and transparency in the promotion of nuclear power.

Promoting continuous implementation of deliberative polling on energy and environmental choices by pro-nuclear advocates will have a significant and major effect on the awareness and attitudes of the general public. When developing trust through the process of deliberation what is important is not the approval of decisions per se but an approach that emphasizes procedural justice in the decision-making process. Such an approach emphasizes fairness and transparency and consequently reestablishes a national feeling of trust in nuclear power ${ }^{17-19)}$.

The relationship between the attitude (for or against) to nuclear use and the attitude towards the usefulness/necessity of nuclear power is a representative awareness with little change. Also, this study showed that the attitude regarding the usefulness/necessity of nuclear power and the sense of safety/anxiety towards nuclear are not so directly related. Making people more aware of the usefulness of nuclear power is an effective way to promote the use of nuclear energy. Making people more aware of the usefulness of nuclear power could be the key to the recommissioning of light water reactors. However, if persuasion about usefulness involves raising public fears about an electricity shortage, this may lead to questions regarding fairness and transparency. For the public to develop a favorable view of nuclear power generation, continuous activities that ensure pro-nuclear advocates act fairly and transparently is an important measure. In order to recommission nuclear power plants, those who are engaged in promoting nuclear power must conduct themselves honestly and honorably based on a strong sense of social responsibility.

\section{Conclusions}

This study analyzed changes in public awareness and attitudes among residents living in the Tokyo metropolitan area over six years prior to and after the Fukushima Accident. The changes caused by the Fukushima Accident must not be considered as transient but as something that transformed people's awareness and attitudes. In particular, there have been marked changes in interest in the use of nuclear power. In this study, the heightened level of interest is seen as a good opportunity. Although we can discern some signs of a return to sense of safety and an 
acceptance of the usefulness of nuclear power, the evidence is not sufficient to make a definitive statement. We need to re-evaluate these matters based on the results of the survey scheduled to be conducted in January 2014.

This study uses some of the results of studies conducted under the Initiatives for Atomic Energy Basic and Generic Strategic Research (2012) and "Efforts in the communication field to go beyond the boundaries of the nuclear power village (2013)."

\section{Notes and Acknowledgements}

The authors were involved in the overall design of the survey including preparation of the survey form, aggregation and analysis of survey results and data management and publication of the survey results. The survey results were managed by a data management working group established under the Social and Environmental Division of the Atomic Energy Society of Japan. Third parties can use individual data and aggregated results provided they comply with the terms of use stipulated by the working group and use them for academic and educational purposes only. The authors participate in the working group as committee members.

Detailed information on the data management working group is provided on the following website. (As of February 2014) http://www.ponpo.jp/DMWG/index.html

The survey sheets of all the surveys and results of simple tabulation including cross tabulation are available on the website. Also, through the website, interested parties can submit an application for the use of survey data.

We have received useful advice and cooperation from Associate Professor Yoshimi Kawamoto of the Department of Nuclear Power and Energy Safety Engineering in the Graduate School of Engineering at the University of Fukui and Specially Appointed Professor Naoki Yamano of the Research Institute of Nuclear Engineering of the University of Fukui. We would like to express our gratitude to them.

Also, we could not have succeeded in conducting the study without the support of the Japan Nuclear Energy Safety Organization and Initiatives for Nuclear System Development and Atomic Energy Basic and Generic Strategic Research. Their allowing us to perform academic survey and disclose data helped dramatically raise the value of this study. We would like to once again express our gratitude.

\section{References}

1) Hiroshi Kimura, "The Gap of Perception towards Nuclear Energy between the Inhabitants in the Tokyo Metropolitan Area and the Members of the Atomic Energy Society of Japan," Journal of the Atomic Energy Society of Japan, 51 [9], 683-685 (2009).

2) Hiroshi Kimura, "What Happened to the Perception Gap between the Inhabitants in the Tokyo Metropolitan Area and the Members of the Atomic Energy Society of Japan Concerning Nuclear Energy since the Fukushima Nuclear Accident," Journal of the Atomic Energy Society of Japan, 54 [9], 606-610 (2012).

3) Cabinet Office, Outline of the "Special Public Opinion Survey on Nuclear Power," http://www8.cao. go.jp/survey/tokubetu/h21/h21-genshi.pdf, 2009 (final confirmation in February 2014).

4) Japan Productivity Center for Socio-Economic Development, 16th (FY 2002) Report on Public Opinion Poll on Energy, 2003.

5) Research Council for Energy and Information Technology, Report on Public Opinion Poll on Energy/ Nuclear Power and International Comparison Thereof, 2004.

6) Institute of Applied Energy, Report on Public Consciousness Survey on Energy in 2009, http://www.iae. or.jp/research/project/gen_2009_r2.pdf, 2009 (final confirmation in February 2014).

7) Institute of Social System (editing), Institute of Nuclear Safety System, Public Opinion of Nuclear 
Power by Data -10-year Continuation Survey-. President Inc., ISBN 4-8334-9098-6, 2004.

8) Japan Atomic Energy Relations Organization, Public Opinion Poll on Knowledge Dissemination and Enlightenment of Nuclear Energy Utilization in 2012. http://www.jaero.or.jp/data/01jigyou/tyousakenkyu.html. 2012 (final confirmation in February 2014).

9) Junko Kitada, "Public Opinion on Nuclear Power Revealed by the Continuation Survey, the Past 30 Years and the Change after the Fukushima Daiichi Nuclear Accident," Transactions of the Atomic Energy Society of Japan, 12[3], 177-196 (2013).

10) Mitsuhiro Yokote, "Result of Public Opinion Poll on Nuclear Power in 2012," Journal of the Atomic Energy Society of Japan, 55 [6], 43-45 (2013).

11) NHK Broadcasting Culture Research Institute, Consciousness Survey on Nuclear Plant and Energy, http://www.nhk.or.jp/bunken/summary/yoron/social/pdf/130523.pdf, 2013 (final confirmation in April 2013.

12) Yoshihiko Shinoda, "Study on the Interaction between Nuclear Power and Society," Transactions of the Atomic Energy Society of Japan, 6[2], 97-112 (2007).

13) Yoshihiko Shinoda, Naoki Yamano, Hiroyuki Torii, "Social Survey on the Relationship between Society and Nuclear Power," Transactions of the Atomic Energy Society of Japan, 7[4], 350-369 (2008).

14) Hirotada Hirose, Change in Public Opinion over Nuclear Power Generation, Document No. 2 of the 27th Nuclear Energy Council, 2013.

15) Tadzuko Kita, "Continuation Opinion Survey on Nuclear Power Generation-Result after One Year after the Mihama Unit 3 Accident-," INSS J, 13, 303 (2006).

16) Discussion Type Opinion Poll on Energy/Environmental Choices. http://www.cas.go.jp/jp/seisaku/npu/ kokumingiron/dp/index.htm. Psychology of Fairness and Procedures, translated by Ikuo Sugawara and Ken`ichi Ofuchi. Plain Publishing (1995).

17) E. Allan Lind et al., Social Psychology of Fairness and Procedures, translated by Ikuo Sugawara and Ken'ichi Ofuchi. Plain Publishing (1995).

18) Satoshi Fujii, Conditions for Creating Trust in Administration, Research on Experimental Social Psychology, 45[1], 27-41 (2005).

19) Susumu Onuma, Yukio Hirose, Kan Nonami, Junkichi Sugiura, Effect of Fairness on Policy Acceptance Case Study on Deliberative Social Decisions in the EU, Collection of Papers of the 48th Annual Conference of Japanese Society of Social Psychology, 2007. 


\section{-Appendix A) Questions concerning public interest in, attitudes to, and awareness of the usefulness/necessity of nuclear power-}

\begin{tabular}{|c|c|c|c|c|c|}
\hline \multirow[t]{3}{*}{$\begin{array}{l}\text { Are you interested in nuclear power or not? Please circle the number of the } \\
\text { response that best represents your opinion from the options on the right. }\end{array}$} & 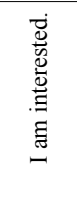 & 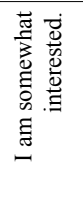 & 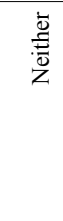 & 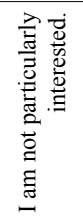 & 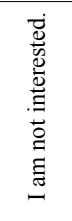 \\
\hline & $\downarrow$ & $\downarrow$ & $\downarrow$ & $\downarrow$ & $\downarrow$ \\
\hline & 1 & 2 & 3 & 4 & 5 \\
\hline \multirow[t]{3}{*}{$\begin{array}{l}\text { Do you think we should continue using nuclear power or stop using it? Please } \\
\text { circle the number of the response that best represents your opinion from the } \\
\text { options on the right. }\end{array}$} & 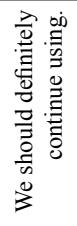 &  & 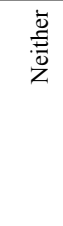 & 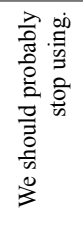 & 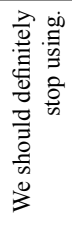 \\
\hline & $\downarrow$ & $\downarrow$ & $\downarrow$ & $\downarrow$ & $\downarrow$ \\
\hline & 1 & 2 & 3 & 4 & 5 \\
\hline \multirow[t]{3}{*}{$\begin{array}{l}\text { Do you think nuclear power is useful or unnecessary for today's society and } \\
\text { our livelihoods? Please circle the number of the response that best represents } \\
\text { your opinion from the options on the right. }\end{array}$} & 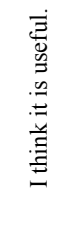 & 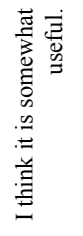 & 离 & 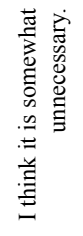 & 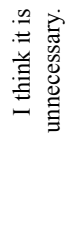 \\
\hline & $\downarrow$ & $\downarrow$ & $\downarrow$ & $\downarrow$ & $\downarrow$ \\
\hline & 1 & 2 & 3 & 4 & 5 \\
\hline \multirow[t]{3}{*}{$\begin{array}{l}\text { Do you feel safe or anxious about the use of nuclear power? Please circle the } \\
\text { number of the response that best represents your opinion from the options on } \\
\text { the right. }\end{array}$} & 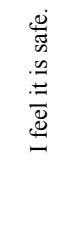 & 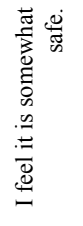 & 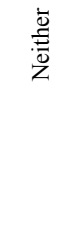 & 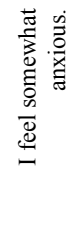 & 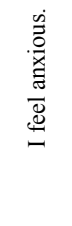 \\
\hline & $\downarrow$ & $\downarrow$ & $\downarrow$ & $\downarrow$ & $\downarrow$ \\
\hline & 1 & 2 & 3 & 4 & 5 \\
\hline
\end{tabular}




\section{-Appendix B) Questions concerning agreement/disagreement about statements on nuclear power use-}

\begin{tabular}{llll}
\hline As for opinions concerning nuclear power use, statements such as & \\
the ones listed below are heard. For each statement, indicate whether \\
you agree or not. Please circle the number of the response that best \\
represents your opinion from the options on the right.
\end{tabular}

The following questions/statements were not used in this study but have been asked in all six surveys. (equivalent to questions)

-We should not extract plutonium, which can be used for nuclear weapons, by reprocessing spent fuel.

-We can provide sufficient electricity without resorting to nuclear power.

- Since nuclear power does not emit $\mathrm{CO}_{2}$ when generating power, it contributes to the prevention of global warming.

- Considering the current electricity generating capacity in Japan, there is no alternative way of generating power in the near future.

-We have to place importance on new energy and human resource developments rather than technology development for nuclear power generation.

- Since there are more nuclear power plants with a long operating life, the level of safety is declining.

-We can use uranium resources semi-permanently for power generation by reprocessing spent fuel.

-We must determine the final repository for high-level radioactive waste as soon as possible.

-We cannot determine the final repository for high-level radioactive waste at the present time. 


\section{- Appendix C) Questions concerning interests and concerns in everyday life-}

Question Which following matters are you usually interested in? Please circle the numbers of the matters (Interests) that you are specifically interested in. You may choose as many answers as you like.

Question What are you usually concerned about? Please circle the numbers of the matters that you are (Concerns) specifically concerned about. You may choose as many answers as you like.

\begin{tabular}{|c|c|}
\hline \multicolumn{2}{|c|}{ Options (matters) are common in "Interests" and "Concerns". } \\
\hline From the first to fourth surveys & After the fifth survey \\
\hline 1. Politics & 1. Politics and economy \\
\hline 2. Price of commodity & 2. Low birthrate and longevity \\
\hline 3. Low birthrate and longevity & 3. Science and technology \\
\hline 4. Science and technology & 4. Energy and resources \\
\hline 5. Energy and resources & 5. Nuclear \\
\hline 6. Nuclear & 6. Environmental issues including global warming \\
\hline 7. Environment & 7. Imported food \\
\hline 8. Global warming & 8. GM food \\
\hline 9. Imported food & 9. Traffic accident \\
\hline 10. GM food & 10. Nuclear-related accident \\
\hline 11. Traffic accidents & 11. Natural disaster \\
\hline 12. Nuclear-related accidents & 12. Crime \\
\hline 13. Natural disasters including earthquake and typhoon & 13. Diplomacy \\
\hline 14. After retirement & 14. Nuclear nonproliferation issue \\
\hline 15. Crime & 15. War and terrorism \\
\hline 16. War & 16. Education \\
\hline 17. Diplomacy & 17. Waste disposal problems \\
\hline 18. Nuclear nonproliferation issues & 18. Radioactive waste disposal problems \\
\hline 19. Terrorism & 19. Sickness \\
\hline 20. Employment & 20. Hobbies and entertainment \\
\hline 21. Education & 21. Volunteer and community activities \\
\hline 22. Waste disposal problems & 22. Others: \\
\hline 23. Radioactive waste disposal problems & \\
\hline 24. Sickness & \\
\hline 25. Hobbies and entertainment & \\
\hline 26. Volunteering and community activities & \\
\hline 27. Others: & \\
\hline
\end{tabular}

Note) After the fifth survey ("Politics" and "Price of commodity"), ("Global warming" and "Environment"), and ("War" and "Terrorism") were integrated into "Politics and economy", "Environmental issues including global warming" and "War and terrorism" respectively. "After retirement" and "Employment" were removed from the list after the fifth survey. 